Acta Crystallographica Section D

\section{Biological \\ Crystallography}

ISSN 0907-4449

\section{Jeffrey A. Bell, Kenneth L. Ho and Ramy Farid*}

Schrödinger, 120 West 45th Street, 17th Floor, New York, NY 10036, USA

Correspondence e-mail: ramy.farid@schrodinger.com
(C) 2012 International Union of Crystallography Printed in Singapore - all rights reserved

\title{
Significant reduction in errors associated with nonbonded contacts in protein crystal structures: automated all-atom refinement with PrimeX
}

\begin{abstract}
All-atom models are essential for many applications in molecular modeling and computational chemistry. Nonbonded atomic contacts much closer than the sum of the van der Waals radii of the two atoms (clashes) are commonly observed in such models derived from protein crystal structures. A set of 94 recently deposited protein structures in the resolution range 1.5-2.8 $\AA$ were analyzed for clashes by the addition of all $\mathrm{H}$ atoms to the models followed by optimization and energy minimization of the positions of just these $\mathrm{H}$ atoms. The results were compared with the same set of structures after automated all-atom refinement with PrimeX and with nonbonded contacts in protein crystal structures at a resolution equal to or better than $0.9 \AA$. The additional Prime $X$ refinement produced structures with reasonable summary geometric statistics and similar $R_{\text {free }}$ values to the original structures. The frequency of clashes at less than 0.8 times the sum of van der Waals radii was reduced over fourfold compared with that found in the original structures, to a level approaching that found in the ultrahigh-resolution structures. Moreover, severe clashes at less than or equal to 0.7 times the sum of atomic radii were reduced 15 -fold. All-atom refinement with PrimeX $X$ produced improved crystal structure models with respect to nonbonded contacts and yielded changes in structural details that dramatically impacted on the interpretation of some protein-ligand interactions.
\end{abstract}

\section{Introduction}

The majority of protein crystal structures are solved in the resolution range $1.7-2.8 \AA$, a resolution range in which the diffraction experiment does not present sufficient information to accurately place individual atoms without additional chemical information. Electron-density peaks specifically for $\mathrm{H}$ atoms are not observed in this resolution range owing to a low signal-to-noise ratio. Therefore, $\mathrm{H}$ atoms are usually not explicitly included in molecular models of protein crystal structures. A molecular model without explicit coordinates for $\mathrm{H}$ atoms is denoted as an united-atom model, in contrast to an all-atom model. United-atom models are frequently insufficient for molecular modeling and computational chemistry applications (such as structure-based virtual screening or lead optimization). How is the gap bridged between current best crystallographic practices and the requirements of these other disciplines for all-atom structures that include hydrogen coordinates?

A brief history of the use of $\mathrm{H}$ atoms and chemical restraints in protein crystal structure refinement is useful before answering this question. Jensen and coworkers (Watenpaugh et al., 1973) first demonstrated that moderate-resolution protein crystal structures could benefit from the reciprocal-
Received 15 February 2012

Accepted 19 April 2012 
space refinement techniques developed for use with crystal structures of small molecules at atomic resolution. They recognized the necessity of using additional chemical information combined with reciprocal-space refinement to accurately determine atomic positions in this situation.

A complete system of geometric restraints was devised for the first widely used protein reciprocal-space refinement program, PROLSQ (Konnert, 1976; Konnert \& Hendrickson, 1980; Hendrickson, 1985). H atoms were not explicitly considered in this system.

The introduction of simulated-annealing refinement led to the widespread adoption of the program X-PLOR (Brünger, 1992). This program featured geometric restraints based on the CHARMM force field (Brünger et al., 1986, 1989; Brünger $\&$ Karplus, 1988). Originally, use of this force field required an all-atom model. CHARMM-based restraints evolved in a way that removed the requirements for hydrogen coordinates. This change was associated with an alteration in the representation of nonbonded contacts from a Lennard-Jones potential to a much simpler repulsive function and the elimination of the use of electrostatic potentials. These modifications were partially motivated by electrostatic artifacts that were introduced into the structural results owing to the lack of an implicit solvent model. In addition, the long time required for computation of the complete set of nonbonded interactions was a significant impediment to the refinement of large crystal structures (Nilges et al., 1988; Weis et al., 1990). By the time that X-PLOR was superseded by the program CNS (Brünger et al., 1998), any requirement for explicit $\mathrm{H}$-atom coordinates for protein crystallographic refinement had been eliminated. However, the capability to apply an electrostatic model and more complete nonbonded interactions in an all-atom model remained an essential part of $C N S$ for the determination of structures from NMR data (Linge et al., 2003).

Engh \& Huber (1991) brought important additional information to the definition of the geometry for protein crystal structures. Their survey of bond lengths and angles observed in small peptide crystal structures at high resolution has been uniformly adopted as a standard against which protein crystal structure models are judged. It has also become the basis for the restraint system in all of the major refinement programs.

Recent developments indicate an interest among crystallographers in the application of more complex descriptions of molecular geometry in refinement to aid in producing better models. The refinement programs REFMAC (Murshudov et al., 2011) and PHENIX (Afonine et al., 2005) may be employed with 'riding $\mathrm{H}$ atoms', even though the ultimate result to be deposited is a united-atom model. (Riding $\mathrm{H}$ atoms are those $\mathrm{H}$ atoms whose positions can be determined unambiguously from the positions of the non- $\mathrm{H}$ atoms; for example, the $\mathrm{H}$ atom attached to the $\mathrm{O}^{\gamma}$ of a serine residue is not a riding $\mathrm{H}$ atom since its position depends on the torsion angle of the $\mathrm{C}^{\beta}-\mathrm{O}^{\gamma}$ bond, while the $\mathrm{H}$ atom on the $\mathrm{C}^{\alpha}$ atom of an amino acid is a riding $\mathrm{H}$ atom, since all torsion angles affecting its position are determined by non- $\mathrm{H}$ atom coordinates.) The advantages of a restraint scheme in which geometric target values for a residue depend on the torsion- angle conformation of the residue backbone have recently been demonstrated (Tronrud et al., 2010). Brunger and coworkers (Fenn et al., 2010, 2011; Schnieders et al., 2011) have combined the all-atom force field AMOEBA with a new refinement scheme and have described the advantages of a more complex molecular description that includes the calculation of electrostatic interactions between protein atoms. Additional recent innovations in the use of geometric information in refinement include the use of deformable elastic network refinement (Schröder et al., 2010), hydropathic forcefield terms (Koparde et al., 2011) and jelly-body restraints (Murshudov et al., 2011).

Structure-validation tools for protein geometry, partially based on the Engh \& Huber standard, are available in several widely used computer programs, most notably PROCHECK (Laskowski et al., 1993), WHAT_CHECK (Hooft, Vriend et al., 1996), NUCheck (Feng et al., 1998) and SFCHECK (Vaguine et al., 1999). These programs address close nonbonded contacts largely from a united-atom perspective. More recently, the structure-validation programs Reduce and MolProbity (Davis et al., 2007; Chen, Arendall et al., 2010) have become important and popular additions to the toolkit of protein crystallographers. They are based on the concept that better judgments can be made as to the correct positioning of certain groups in the model after the addition of $\mathrm{H}$ atoms to a united-atom protein crystal structure and after observing their interactions. Within their software system, interpenetration of van der Waals molecular surfaces by $0.4 \AA$ or more constitutes a clash. The authors flatly state that

Such large overlaps cannot occur in the actual molecule, but mean that at least one of the two atoms is modeled incorrectly

(Chen, Arendall et al., 2010).

At this point, the question of the source of all-atom models needed for computational work can be addressed more clearly. Currently, such all-atom models are produced by adding $\mathrm{H}$ atoms to the united-atom models produced by crystallography. For water molecules and for protein $\mathrm{H}$ atoms whose position is subject to some degree of freedom, i.e. non-riding $\mathrm{H}$ atoms, either a force-field-dependent or a rule-based method is employed to determine the positions of these $\mathrm{H}$ atoms in order to avoid close nonbonded contacts and to form hydrogen bonds as appropriate. Nevertheless, when $\mathrm{H}$ atoms are added in this way to a very large majority of protein crystal structures deposited in the Protein Data Bank (Berman et al., 2000), multiple close nonbonded contacts between atoms are observed. One goal of this work is to document this observation and to try to understand why such interactions occur, the recent focus on protein structure validation with $\mathrm{H}$ atoms present notwithstanding.

The usual remedy in computational chemistry to these highenergy close contacts is to minimize the coordinates of the allatom model against a force field, with non- $\mathrm{H}$ atoms restrained to their positions in the crystallography-derived model so that they do not deviate too far from their experimentally determined positions. This solution is less than ideal, because the method produces no feedback as to whether the all-atom 
model is still consistent with the experimental data. In other words, one does not know how far is too far. This procedure could be especially dangerous if the original clashes were caused by atoms that were significantly misplaced.

The refinement program Prime $X$ was implemented partially in response to these issues. It applies well established methods of protein crystal structure refinement (Bell et al., 2012) combined with the all-atom OPLS force field (Jorgensen et al., 1996; Kaminski et al., 2001; Banks et al., 2005) for geometric restraints. Aside from the presence or absence of $\mathrm{H}$ atoms in the model, these OPLS-based restraints differ in two specific respects from what have become the traditional restraint systems: (i) a Lennard-Jones description of both the attractive and repulsive components of van der Waals interactions replaces the simpler repulsive term of most Engh and Huberbased restraints and (ii) electrostatic interactions are treated, including a Surface Generalized Born model to account for implicit solvent effects (Ghosh et al., 1998; Gallicchio et al., 2002; Zhu et al., 2007; Li, Abel et al., 2011). The net effect of these differences is very significant. In a simpler restraint system, the bond-length targets are each a function of a single parameter according to the atom types involved in the bond. A similar situation occurs for bond angles. However, the bondlength and bond-angle targets specified by OPLS are a function of several parameters that can all affect a single bond length or bond angle. In other words, the restraint target for a particular bond length (or angle) is contingent on the local environment of the atoms involved. Touw \& Vriend (2010) have shown that at least one type of protein bond angle is a complex function of the local environment and is not well described by a single Engh \& Huber (1991) target angle. The target geometric values in the well characterized restraint system of Karplus and coworkers depend on the local backbone conformation of the protein (Tronrud et al., 2010). That any particular force field can reproduce all such dependencies remains to be demonstrated, but potentially a force-fieldbased restraint system can more effectively adapt to local environments than current protein crystallography restraint systems.

Refinement of protein crystal structures with an all-atom model and a complete force field does much more than avoid errors whose remediation may seriously degrade the accuracy of the coordinates. The more detailed accounting for nonbonded interactions within the protein used in Prime $X$ can also produce a direct positive effect during refinement. While even small changes in the structure near a ligand-binding site can be critical for structure-based drug discovery, examples are presented to show how refinement with an all-atom model can result in large coordinate improvements at such sites.

\section{Methods}

\subsection{Data-set selection}

The members of the moderate-resolution protein data set used in this study were selected from the Protein Data Bank (Berman et al., 2000). Candidate structures were limited to those deposited in 2010 to ensure that refinement followed modern practices and that sufficient time had passed for structures to be withdrawn if found to contain gross errors. Reflection data were required to have been deposited with the coordinates. Each entry was restricted to contain one or more protein chains but no DNA or RNA. The reported $R_{\text {free }}$ values were limited to 0.28 or lower. Structures were required to have a high-resolution limit between 1.5 and $2.8 \AA$. The molecular mass of protein within the asymmetric unit was limited to be between 10 and $300 \mathrm{kDa}$. Proteins with homologous sequences were removed at $30 \%$ identity.

In addition, the Prime $X$-calculated $R_{\text {free }}$ was required to exceed the $R$ value by at least 0.008 . This requirement ensured that the test set deposited in the PDB was likely to be the one that was actually used in the refinement of the deposited coordinates. (The $R_{\text {free }}$ calculated using the deposited test set was found to actually be lower than the calculated $R$ factor in several cases, strongly indicating that the deposited test set was not used in the final refinement of the deposited coordinates.) Others have made similar observations about test-set entries in the PDB (Joosten et al., 2009; Afonine et al., 2010). A meaningful comparison of $R_{\text {free }}$ values was not possible without using a single consistent test set.

The high-resolution reference data set used in this study was selected from the PDB with the following restrictions: (i) the deposition of diffraction data was required, (ii) coordinate sets were selected from entries containing protein but no DNA or RNA and with a high-resolution limit of $0.9 \AA$ or better, (iii) proteins with homologous sequences were removed at $30 \%$ identity and (iv) only proteins refined with coordinates for $\mathrm{H}$ atoms were included in this set.

\subsection{Prime $X$ crystallographic calculations and refinement}

The key features of Prime $X$ crystal structure refinement have been described in some detail elsewhere (Bell et al., 2012). Only details relevant to this work are described below.

2.2.1. Restrained reciprocal-space minimization. Reciprocalspace coordinate minimization is applied in PrimeX with a maximum-likelihood target, using the formulation of Pannu \& Read (1996). The PrimeX implementation follows the general concepts developed by Brünger and coworkers (Brünger, 1989; Brünger et al., 1998). A maximum-likelihood target has been shown to improve the convergence of refinement and to reduce the effects of model bias (Murshudov et al., 1997).

OPLS 2005 (Jorgensen et al., 1996; Kaminski et al., 2001; Banks et al., 2005) is a general-purpose force field for modeling proteins, nucleic acids and small molecules. Prime $X$ applies this consistent molecular description as geometric restraints during the refinement of the atomic positions for all molecular components of large biological crystal structures. Restrained isotropic $B$-factor refinement is applied in PrimeX $X$ using an approach similar to that used in the program $C N S$ (Brünger $e t$ al., 1989).

Because of its dependence on the OPLS force field, PrimeX operates on all-atom models at all stages of refinement. $\mathrm{H}$-atom coordinates do not participate in crystallographic 
calculations and are not influenced directly by the diffraction data. The advantage of this approach is that the underdetermined nature of the crystallographic refinement calculation is not made worse by the many more parameters for $\mathrm{H}$-atom coordinates and $B$ factors. $\mathrm{H}$-atom positions are a function of the force field acting on all atoms, while the positions of non-H atoms are refined under the joint influence of crystallographic and force-field gradients. Thus, the $\mathrm{H}$-atom coordinates are not biased towards the centre of mass of the electron-density distribution, as may occur in some forms of all-atom refinement (Coulson \& Thomas, 1971).

For $\mathrm{H}$ atoms bonded to more electronegative atoms, electrostatic forces are a major determinant of nonbonded interactions and they must be evaluated during the calculation of geometric gradients in the refinement. Thus, Prime $X$ employs the complete molecular-mechanics description of atomic interactions embodied in OPLS, including electrostatic terms (Jorgensen et al., 1996; Kaminski et al., 2001; Banks et al., 2005). Also included in the current Prime $X$ calculations was an optional implicit solvation term (Ghosh et al., 1998; Gallicchio et al., 2002; Zhu et al., 2007).

An overview of the OPLS force field, and a description of the details of the second-generation Surface Generalized Born model used to implicitly account for solvation effects, have been provided by $\mathrm{Li}$, Abel et al. (2011). Both the electrostatic and solvation calculations employ residue-based cutoffs of $15 \AA$ for long-range interactions between neutral residues, of $30 \AA$ between charged residues and of $20 \AA$ between mixed charged and neutral residues. Such approximations and model features should be considered in the context of a trade-off between computational time and rigorous calculations, as discussed by Moulinier et al. (2003), who pioneered the use of the Generalized Born approach in refinement, and by Fenn $e t$ al. (2011), who have advocated the use of an alternate electrostatic model in refinement. Refinement incorporating a complete electrostatic description has been shown to lead to lower $R_{\text {free }}$ values compared with refinement excluding these interactions (Knight et al., 2008; Fenn et al., 2010, 2011; Schnieders et al., 2011).

2.2.2. Simulated-annealing refinement. Simulated-annealing refinement within Prime $X$ is implemented through the generalpurpose molecular-modeling package IMPACT (Banks et al., 2005), employing concepts for simulated-annealing refinement validated in the program CNS (Adams et al., 1997). PrimeX simulated annealing provides two alternative energy models for dynamic simulation refinement. In the complete energy model, all molecular-mechanics terms are evaluated during the simulation. In the approximate method, the electrostatic and implicit solvation terms are not evaluated, a method similar to that employed in CNS (Adams et al., 1997). All calculations in this work involved the complete energy model.

2.2.3. Electron-density map calculations. Map calculations in Prime $X$ are based on the SIGMAA weighting scheme of Read (1986), a data treatment that has been shown to decrease the bias in electron-density maps.

2.2.4. Hydrogen-bond network optimization. An additional hydrogen-bond optimization tool in Prime $X$ analyzes the locations of hydrogen-bond donors and acceptors to define clusters of such sites that might be connected through hydrogen bonds. Within each cluster, hydrogen bonding is evaluated using a rule-based method to find an optimal combination of the variable components of these systems. The structural features adjusted during hydrogen-bond optimization are (i) alcoholic $\mathrm{H}$-atom positions; (ii) sulfhydryl $\mathrm{H}$-atom positions; (iii) phenolic $\mathrm{H}$-atom positions; (iv) charge and tautomeric states of aspartic acid and glutamic acid side chains; (v) charge states, tautomeric states and orientation (flip) of histidine side chains; (vi) orientation (flip) of asparagine and glutamine side chains; and (vii) positions of $\mathrm{H}$ atoms in water molecules. The goal of this procedure is to minimize the energy of the system by maximizing the number of hydrogen bonds while avoiding close high-energy nonbonded interactions. This is accomplished by enumerating plausible orientations for each rotatable hydrogen and water molecule by identifying nearby hydrogen-bond donors and acceptors. Initial solutions for the overall local hydrogen-bond network are then generated by iteratively choosing the optimal state for each species in turn until convergence, starting from a variety of random starting conditions. These initial solutions are then recombined with each other and further optimized via simulated annealing. The best solution obtained overall is then chosen. The hydrogen-bond optimization tool in PrimeX performs essentially the same tasks as a number of other hydrogen-bond optimization tools such as NETWORK (Hooft, Sander et al., 1996) and Reduce (Word et al., 1999).

2.2.5. The polish refinement workflow. The all-atom structures produced by PrimeX refinement, as described in Table 4, were the result of application of the 'polish' workflow to the united-atom models obtained from the PDB without any human intervention during the refinement process. The refined coordinates that were the result of this process are archived at http://www.schrodinger.com/primex.

The purpose of the polish workflow is to produce the best all-atom model possible that is consistent with the diffraction data, starting with an already well refined crystal structure. The workflow applies reciprocal-space optimization of coordinates and thermal factors, simulated-annealing refinement and hydrogen-bond optimization in an automated manner as described below. It does not have as a purpose the remediation of more serious errors in crystal structure fitting such as the choice of the wrong side-chain rotamer, mis-identification of protein electron density as part of the solvent model or the rebuilding of misplaced side chains, which would require the application of additional fitting functions.

Bond orders are first assigned throughout the structure and $\mathrm{H}$ atoms are added. Initial analysis of the input structure provides basic crystallographic statistics for the structure using the bulk water correction in PrimeX (the flat model of Jiang \& Brünger, 1994) and overall anisotropic scaling. A detailed analysis of close nonbonded contacts for the input structure is also provided.

As a next step, reciprocal-space minimization is applied at increasing weight on the $\mathrm{X}$-ray terms $\left(w_{\mathrm{A}}\right)$ in order to optimize this weight for subsequent refinement. The value selected 
corresponds to the weight employed when the minimum $R_{\text {free }}$ value is observed. The weights selected for this set of proteins ranged between 0.25 and 1.73 . Issues surrounding the selection of restraint weights when using an all-atom force field have been discussed by Fenn \& Schnieders (2011). B-factor restraint weights $\left(w_{\mathrm{B}}\right)$ are estimated from the high-resolution limit $(r)$ of the diffraction data according to the equation

$$
w_{\mathrm{B}}=w_{\mathrm{A}} 10^{2(r-2.2)} .
$$

The functional form of this equation was chosen based on the known $B$-factor restraint-weight requirements in Prime $X$ at the bounds of the usual resolution range for refinement. For a low-resolution structure of $2.7 \AA$ or worse, a weight of at least ten times $w_{\mathrm{A}}$ is required. For refinement at high resolution (better than $1.7 \AA)$, a very low $B$-factor restraint weight $(<0.1$ times $w_{\mathrm{A}}$ ) is required. The values of the two constants in the equation were varied while observing the $R$ factors from refinement in a broad resolution range. The current equation was observed to be as effective within PrimeX $X$ as stepwise optimization of $w_{\mathrm{B}}$ as described for $w_{\mathrm{A}}$ above and required much less computational time. Continued development of this method, such as the exploration of any effect of noncrystallographic symmetry restraints, will be reported in future work. Although this equation is the default method for assigning $B$-factor restraint weights in the polish workflow, stepwise optimization of this value is provided as an option. Also, minimization performed during weight optimization may optionally be applied towards progress in the refinement of the structure.

An initial optimization of hydrogen-bond orientation is applied and is followed by separate coordinate and $B$-factor reciprocal-space minimization steps. The model is then refined with a defined set of operations comprised of reciprocal-space coordinate minimization, hydrogen-bond optimization, reciprocal-space coordinate/ $B$-factor minimization, simulated annealing and a final reciprocal-space coordinate $/ B$-factor minimization. The optimization of $\mathrm{X}$-ray and $B$-factor restraint weights as described above is repeated after this first refinement round. The same defined set of refinement procedures is then repeated twice more but without simulated annealing.

\subsection{Direct generation of all-atom models from selected structures}

To generate the all-atom models described in Table 3, $\mathrm{H}$ atoms were added to united-atom models from the PDB and the positions of the $\mathrm{H}$ atoms were optimized using the hydrogen-bond network optimization function described above (\$2.2.4) as implemented in the Protein Preparation Wizard (Maestro v.9.2; Schrödinger LLC). The positions of all $\mathrm{H}$ atoms were then also optimized through energy minimization against the OPLS force field, with the positions of all heavier atoms held fixed.

\subsection{Structure-validation calculations}

2.4.1. Clash detection and van der Waals radii. The Rowland \& Taylor (1996) compilation of van der Waals radii was employed in this study. It was based on an analysis of 28403 structures in the Cambridge Structural Database (Allen, 2002). Their results agreed well with the frequently cited van der Waals radii derived by Bondi (1964) when the available solid-state structural data were not nearly so extensive. The largest difference between the two studies was that the radius of the $\mathrm{H}$ atom was determined to be $1.1 \AA$ rather than $1.2 \AA$ as in the older work.

As observed by Rowland \& Taylor (1996), atoms may at times have nonbonded interactions somewhat less than the sum of their van der Waals radii. For the purposes of this work, a center-to-center distance of less than or equal to 0.8 times the sum of the van der Waals radii was defined as a 'clash'. A reasonable conclusion from the selection of data presented by Rowland and Taylor is that interatomic distances of less than or equal to 0.7 times the sum of van der Waals radii are rare. Such interactions were denoted as 'severe clashes' in this work.

The current work focuses specifically on interactions among atoms within the proteins since this issue is the central concern for computational chemistry applications. Close interactions with water and solvent molecules will be the focus of future work. Clashes generated from symmetry considerations were not counted for observations on the moderate-resolution data set since they are not optimized by the version of the Protein Preparation Wizard used in this study.

Interatomic contacts were calculated after removing hydrogen bonds from consideration. Because of the lack of certainty regarding the positions of $\mathrm{H}$ atoms, all donoracceptor atom pairs that could potentially be involved in a hydrogen bond were also excluded from the list of close contacts, even if an $\mathrm{H}$ atom was not found directly between them. This conservative approach avoided over-reporting as clashes any interactions that might actually be hydrogen bonds. Where alternate conformations were found, only the conformation with the higher occupancy was considered for the calculation of clashes.

The definition of a clash most commonly used in protein crystallography derives from the work of Jane Richardson, David Richardson and coworkers (Word et al., 1999; Davis et al., 2007; Chen, Arendall et al., 2010). It is simply the overlap of two van der Waals surfaces by $0.4 \AA$ or more. It is employed with an atomic radius of $1.00 \AA$ for polar and aromatic $\mathrm{H}$ atoms and a radius of $1.17 \AA$ for all other $\mathrm{H}$ atoms, resulting in clashes between two $\mathrm{H}$ atoms with the same radii at separations of 1.60 and $1.94 \AA$, respectively. Clashes between two $\mathrm{H}$ atoms in the current work occur at a separation of 0.8 times the sum of their van der Waals radii, i.e. $1.76 \AA$. For most other atoms the definition applied here is less strict than that applied by the Richardson group. The one exception is for $\mathrm{O}$ atoms, which have a smaller radius in the Richardson system, resulting in clashes between two $\mathrm{O}$ atoms at $2.40 \AA$ separation compared with $2.53 \AA$ in the current work. The Richardson atomic parameters were designed from various theoretical and practical considerations (Word et al., 1999) to yield a system in which all observed clashes were exceptional. The approach in the current work was to use the values for atomic radii 
Table 1

Characteristics of ultrahigh-resolution protein structures.

\begin{tabular}{|c|c|c|c|c|c|c|c|c|c|c|c|}
\hline \multirow[b]{2}{*}{$\begin{array}{l}\text { PDB } \\
\text { code }\end{array}$} & \multirow[b]{2}{*}{ 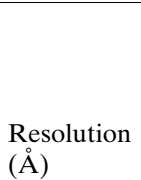 } & \multirow[b]{2}{*}{$\begin{array}{l}\text { No. of } \\
\text { residues }\end{array}$} & \multirow{2}{*}{$\begin{array}{l}\text { Bond- } \\
\text { length } \\
\text { r.m.s.d. } \\
(\AA)\end{array}$} & \multirow{2}{*}{$\begin{array}{l}\text { Bond- } \\
\text { angle } \\
\text { r.m.s.d. } \\
\left({ }^{\circ}\right)\end{array}$} & \multirow{2}{*}{$\begin{array}{l}\text { Side-chain } \\
\text { planarity } \\
\text { r.m.s.d. } \\
(\AA)\end{array}$} & \multirow{2}{*}{$\begin{array}{l}\omega \text {-Angle } \\
\text { standard } \\
\text { deviation } \\
\left(^{\circ}\right)\end{array}$} & \multirow[b]{2}{*}{ Clashes $\dagger$} & \multirow[b]{2}{*}{$\begin{array}{l}\text { Severe } \\
\text { clashesł }\end{array}$} & \multicolumn{2}{|c|}{ 'Corrected' } & \multirow[b]{2}{*}{ Reference } \\
\hline & & & & & & & & & Clashes $\dagger$ & $\begin{array}{l}\text { Severe } \\
\text { clashes } \ddagger\end{array}$ & \\
\hline 1byz & 0.90 & 52 & 0.019 & 2.0 & 0.006 & 2.9 & 0 & 1 & 0 & 0 & Privé et al. (1999) \\
\hline 1dy5 & 0.87 & 248 & 0.020 & 2.6 & 0.013 & 6.6 & 8 & 2 & 2 & 0 & Esposito et al. (2000) \\
\hline $1 \mathrm{i} 1 \mathrm{w}$ & 0.89 & 303 & 0.041 & 2.9 & 0.016 & 6.4 & 1 & 2 & 0 & 0 & Natesh et al. (2003) \\
\hline $1 \mathrm{p} 9 \mathrm{~g}$ & 0.84 & 41 & 0.017 & 2.4 & 0.009 & 6.7 & 0 & 0 & 0 & 0 & Xiang et al. (2004) \\
\hline 1ucs & 0.62 & 64 & 0.014 & 2.2 & 0.010 & 5.3 & 0 & 1 & 0 & 0 & Ko et al. (2003) \\
\hline $1 \mathrm{vyr}$ & 0.90 & 364 & 0.017 & 2.3 & 0.012 & 5.8 & 0 & 0 & 0 & 0 & Khan et al. (2004) \\
\hline $1 \mathrm{yk} 4$ & 0.69 & 52 & 0.022 & 2.7 & 0.011 & 5.7 & 2 & 3 & 0 & 0 & Bönisch et al. (2005) \\
\hline $2 \mathrm{~b} 97$ & 0.75 & 142 & 0.028 & 2.8 & 0.016 & 7.6 & 2 & 0 & 0 & 0 & Hakanpää et al. (2006) \\
\hline $2 \mathrm{~h} 5 \mathrm{c}$ & 0.82 & 198 & 0.025 & 2.4 & 0.015 & 7.3 & 2 & 0 & 2 & 0 & Fuhrmann et al. (2006) \\
\hline 2vb1 & 0.65 & 129 & 0.021 & 3.1 & 0.012 & 7.1 & 1 & 0 & 0 & 0 & Wang et al. (2007) \\
\hline $3 \mathrm{mi} 4$ & 0.80 & 223 & 0.028 & 2.5 & 0.015 & 6.8 & 3 & 3 & 1 & 0 & $\begin{array}{l}\text { A. Brzuszkiewicz, M. Dauter \& } \\
\text { Z. Dauter (unpublished work) }\end{array}$ \\
\hline \multirow{2}{*}{\multicolumn{2}{|c|}{$\begin{array}{l}\text { Total } \\
\text { Mean }\end{array}$}} & 3543 & & & & & 52 & 21 & 21 & 1 & \\
\hline & & & 0.021 & 2.5 & 0.011 & 6.4 & 15 & 06 & 06 & 003 & \\
\hline
\end{tabular}

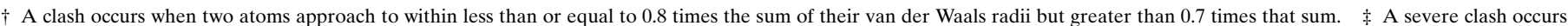
when two atoms approach to within less than or equal to 0.7 times the sum of their van der Waals radii.

(Rowland \& Taylor, 1996) unadjusted and to observe from ultrahigh-resolution protein structures how frequently clashes might reasonably be expected to occur owing to the local molecular environment.

2.4.2. Calculation of summary geometry statistics. Bondlength, bond-angle and torsion-angle statistics were calculated in NUCheck (Feng et al., 1998). Side-chain group planarity deviation was calculated using the Protein Reports utility in PrimeX.

\section{Results}

\subsection{Ultrahigh-resolution structures}

Before exploring the close contacts (clashes and severe clashes as defined above) and structural geometry at moderate resolution, some perspective can be obtained on summary geometric statistics and the occurrence of clashes from ultrahigh-resolution protein structures.

3.1.1. Clashes and severe clashes. Table 1 shows observations from 18 X-ray crystal structures with at least $0.9 \AA$ resolution which were refined (by the authors of the respective structures) with $\mathrm{H}$ atoms present. (At this resolution hydrogen positions may have been guided by electron density, although electron density need not have been observed for all $\mathrm{H}$ atoms.) Over the entire set of structures, 'clashes' and 'severe clashes' were observed with a frequency of 1.5 and 0.6 occurrences per 100 residues, respectively.

All of the observed clashes were examined individually to determine their origin. The results are presented in Table 2.
Table 2

Classification of clashes and severe clashes requiring correction in Table 1.

\begin{tabular}{ll}
\hline Classification & $\begin{array}{l}\text { No. of clashes } \\
\text { and severe } \\
\text { clashes }\end{array}$ \\
\hline $\begin{array}{l}\text { Hydroxyl (or sufhydryl) group: rotation around carbon- } \\
\text { oxygen (sulfur) bond relieves clash }\end{array}$ & 27 \\
$\begin{array}{l}\text { Mistake in positioning of non-H atoms in the electron } \\
\text { density }\end{array}$ & 15 \\
$\begin{array}{l}\text { Flip of asparagine or glutamine residue relieves clash } \\
\text { Flip or alternate tautomer of histidine residue relieves } \\
\text { clash }\end{array}$ & 4 \\
\hline
\end{tabular}

In $37 \%$ of the clashes a chemically implausible interaction was observed in which a hydroxyl or sulfhydryl $\mathrm{H}$ atom pointed directly at another $\mathrm{H}$ atom. The positions of these $\mathrm{H}$ atoms were not supported in any obvious way by the observed electron density. The most likely explanation is that these hydrogen positions were oversights in the model-building process. In addition, $21 \%$ of the close interactions identified occurred at positions where the heavy atoms to which the $\mathrm{H}$ atoms were attached did not fit the electron density well and appeared to be incorrectly positioned. Clashes were included in this category only if the electron-density map provided reasonable doubt as to the correctness of the structure and suggested a more attractive alternate position. A further $12 \%$ of close contacts could be removed by flipping or changing the tautomer of an asparagine, glutamine or histidine side chain.

Ultimately, only $30 \%$ of the observed clashes withstood critical examination and avoided being included in Table 2. In Table 1, the 'corrected' columns offer a better estimate of 
the close contacts actually present in the structures. Thus, the frequency of bona fide 'clashes' and 'severe clashes' was 0.6 and 0.03 per 100 residues, respectively. Note that the second value is based on just a single observation (one severe clash in 2xu3).

3.1.2. Summary geometry statistics. The average r.m.s. deviations (r.m.s.d.s) of bond lengths and angles with respect to the Engh \& Huber (1991) standard were $0.021 \AA$ and $2.5^{\circ}$, respectively (Table 1). The significance of the former number might be questioned since at this resolution the refined bond lengths are likely to reflect the effects of restraints. However, atomic positions are observed accurately enough at this resolution such that bond angles can be precisely determined from the crystallographic results. Thus, the latter value may be significant. However, two observations must be considered in interpreting this bond-angle value. Firstly, the program SHELX (Sheldrick \& Schneider, 1997) may apply bond-angle restraints (as 1,3-atom distance restraints) during refinement, although published information rarely allows one to deduce the effect of these possible restraints on bond angles. Normally, one might expect the net effect of restraints would be to narrow the distribution of values observed. At the same time, a critical observation is that high-resolution protein crystal structures very frequently have r.m.s. $Z$ scores (Spronk et al., 2004) greater than 1 , i.e. the standard deviation of bond angles for these structures are greater than what would be predicted from the work of Engh \& Huber (1991). This observation (Joosten et al., 2009) is generally interpreted to mean that the bond angles are too widely distributed in very high resolution structures, possibly because these restraints are faulty owing to variations in bond lengths at high resolution. The possibility that the Engh and Huber parameters predict too narrow a distribution owing to biases in the smallmolecule structures from which the parameters were derived is generally discounted.

The average r.m.s.d. from planarity for side-chain groups was $0.011 \AA$ and the average standard deviation of the $\omega$ angle was $6.4^{\circ}$. For similar reasons, these two values may be considered to be reference points for the geometry of models at moderate resolution.

\subsection{Moderate-resolution crystal structures as deposited}

94 crystal structures with a broad range of sizes from several different refinement programs were examined (Table 3). Their most important common characteristics were recent deposition in the PDB and falling into the most highly populated resolution range typical for protein crystal structures (see $\$ 2$ for further details on the selection of this data set).

3.2.1. Clashes and severe clashes. The occurrence of close contacts was enumerated after addition of $\mathrm{H}$ atoms and after careful optimization of $\mathrm{H}$-atom positions without changing the coordinates of any non-H atoms. Table 3 shows the frequency of clashes and severe clashes for each protein. Their rates of occurrence per 100 residues were observed in a very broad range from 20.4 (3lpf) to 0.0 (three instances) and from 2.9 (3lpf) to 0.0 (35 instances) for clashes and severe clashes, respectively. Overall, clashes in the moderate-resolution structure set were observed at a frequency of 4.0 per 100 residues, over six times the rate of bona fide clashes in the ultrahigh-resolution set. Severe clashes were observed at a frequency of 0.5 per 100 residues, compared with 0.03 for bona fide severe clashes for the reference ultrahigh-resolution data set (Table 1).

3.2.2. Summary geometry statistics. As shown in Table 3 , the bond-length r.m.s.d.s for the set of proteins varied over a wide range, from $0.004 \AA$ for 3 phe to $0.031 \AA$ for 3 lje, with an average of $0.014 \AA$. Bond-angle r.m.s.d.s varied from a minimum of $0.6^{\circ}$ (3ni0) to a maximum of $2.5^{\circ}$ (3nof), with an average of $1.4^{\circ}$. The average r.m.s.d. for side-chain group planarity was $0.005 \AA$ and the average peptide torsion-angle standard deviation was $5.1^{\circ}$. A more detailed examination and comparison of these summary statistics follows in \$3.3.2.

\subsection{All-atom refinement with PrimeX}

3.3.1. Clashes and severe clashes. The additional all-atom refinement in PrimeX $X$ applied to the moderate-resolution data set produced the structures characterized in Table 4. The frequency of regular clashes overall was 0.9 per 100 residues, which is well below the frequency originally observed for the ultrahigh-resolution set (1.5 per 100 residues; Table 1$)$, but somewhat higher than the corrected value of 0.6 per 100 residues. The frequency of clashes overall was decreased more than fourfold from all-atom models derived from the coordinates as originally deposited. The frequency of severe clashes overall was 0.03 per 100 residues, the same value as obtained for the corrected ultrahigh-resolution structures (Table 1) and 17-fold lower than the frequency in the otherwise remediated moderate-resolution structures (Table 3). Seven of the 94 structures had neither type of clashes after all-atom refinement. All structures without clashes were solved at $2.2 \AA$ resolution or better. 39 of the 94 structures had both no severe clashes and a lower frequency of clashes than the corrected ultrahigh-resolution structures.

Each of the residual clashes in the Prime $X$-refined set was inspected with reference to a $2 F_{\mathrm{o}}-F_{\mathrm{c}}$ composite OMIT map. Clear evidence of a better alternate interpretation of the electron density was present for $14 \%$ of the close contacts, owing to either large problems with the main-chain fit or to the need for a substantially different side-chain rotamer. Subtracting the number of clashes attributable to these issues from the total clashes provided an estimate of the frequency of bona fide regular clashes as 0.7 clashes per 100 residues, approaching the corrected frequency found in the ultrahighresolution structure set ( 0.6 clashes per 100 residues). Within this structural survey, many situations were observed to be ambiguous and were not counted. Thus, the level of clashes owing to model errors might actually have been somewhat higher. A very time-intensive comprehensive re-refinement of the structures would be required to confirm this suspicion, which is beyond the scope of the present work.

Clash frequencies derived from Tables 1,3 and 4 are compared in Table 5, as well as with respect to the various 
Table 3

Statistics for structures of moderate-resolution data in the PDB.

Bond- Bond- Side-chain $\omega$-Angle

length angle planarity standard

PDB Resolution No. of Refinement r.m.s.d. r.m.s.d. r.m.s.d. deviation $R$

PDB Resolution No. of Refinement r.m.s.d. r.m.s.d. r.m.s.d. deviation $R \quad$ Severe

\begin{tabular}{|c|c|c|c|c|c|c|c|c|c|c|}
\hline code & $(\AA)$ & residues & program & $(\AA)$ & $\left({ }^{\circ}\right)$ & (§) & $\left({ }^{\circ}\right)$ & factor $\dagger$ & $R_{\text {free }}{ }^{\dagger}$ & Clashes $\ddagger$ \\
\hline $2 \times 3 k$ & 2.50 & 1145 & REFMAC & 0.015 & 1.5 & 0.004 & 6.7 & 0.216 & 0.266 & 58 \\
\hline $2 \mathrm{xda}$ & 1.85 & 150 & REFMAC & 0.014 & 1.3 & 0.005 & 5.7 & 0.189 & 0.216 & 2 \\
\hline $2 \times n 8$ & 1.64 & 409 & REFMAC & 0.023 & 1.8 & 0.009 & 6.2 & 0.181 & 0.220 & 6 \\
\hline $2 \mathrm{xpp}$ & 1.74 & 161 & REFMAC & 0.018 & 1.6 & 0.005 & 4.8 & 0.208 & 0.252 & 5 \\
\hline $2 \times 56$ & 2.09 & 166 & REFMAC & 0.007 & 1.0 & 0.002 & 4.9 & 0.219 & 0.258 & 4 \\
\hline $2 \mathrm{xsn}$ & 2.68 & 1341 & BUSTER & 0.013 & 1.6 & 0.008 & 2.8 & 0.224 & 0.260 & 13 \\
\hline
\end{tabular}

1341 BUSTER $0.013 \quad 1.6$ 0.008

$\begin{array}{llllll}179 & \text { REFMAC } & 0.009 & 1.2 & 0.004 & 5.4 \\ 666 & \text { PHENIX } & 0.011 & 1.3 & 0.004 & 5.6 \\ 869 & \text { REFMAC } & 0.015 & 1.5 & 0.007 & 5.9\end{array}$

2xsq 1.72

2xsw 1.90

2xsx 1.70

\section{9}

\author{
Schmelz (2010) \\ Paz et al. (2011) \\ Ouellet et al. (2011) \\ Diebold et al. (2010) \\ J. R. C. Muniz, C. D. O. Cooper, W. W. Yue, \\ E. Krysztofinska, F. Vondelft, S. Knapp, \\ O. Gileadi, C. H. Arrowsmith, \\ A. M. Edwards, J. Weigelt, C. Bountra, \\ K. L. Kavanagh \& U. Oppermann \\ (unpublished work)
}

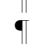

M. Vollmar, E. Krysztofinska, A. Chaikuad,

T. Krojer, R. Cocking, F. Vondelft,

C. Bountra, C. H. Arrowsmith, J. Weigelt, A. Edwards, W. W. Yue \& U. Oppermann (unpublished work)

\begin{tabular}{|c|c|c|c|c|c|c|c|c|c|c|c|c|}
\hline $2 \mathrm{xu} 7$ & 1.90 & 752 & $R E F M A C$ & 0.023 & 1.8 & 0.008 & 7.1 & 0.211 & 0.245 & 14 & 1 & Lejon et al. (2011) \\
\hline 2xul & 2.20 & 645 & REFMAC & 0.029 & 2.0 & 0.005 & 6.5 & 0.196 & 0.235 & 20 & 1 & Fokina et al. (2010) \\
\hline $2 \mathrm{xvs}$ & 1.80 & 166 & REFMAC & 0.016 & 1.5 & 0.007 & 5.8 & 0.200 & 0.249 & 0 & 0 & Adams et al. (2012) \\
\hline $2 x v v$ & 2.40 & 582 & CNS & 0.007 & 1.2 & 0.005 & 1.0 & 0.211 & 0.252 & 35 & 1 & Ryan et al. (2011) \\
\hline $2 x x j$ & 1.96 & 1239 & PHENIX & 0.007 & 1.0 & 0.003 & 9.0 & 0.190 & 0.237 & 27 & 3 & $\begin{array}{l}\text { J. Tickle, E. De Mendoza Barbera \& } \\
\text { F. M. D. Vellieux (unpublished work) }\end{array}$ \\
\hline 3acw & 1.63 & 284 & REFMAC & 0.007 & 1.5 & 0.006 & 4.9 & 0.228 & 0.252 & 5 & 0 & Lin et al. (2010) \\
\hline 3aey & 1.92 & 698 & $C N S$ & 0.005 & 1.2 & 0.004 & 1.2 & 0.192 & 0.214 & 29 & 5 & Murakawa et al. (2011) \\
\hline 3ajx & 1.60 & 828 & $C N S$ & 0.004 & 1.2 & 0.004 & 1.3 & 0.198 & 0.218 & 8 & 0 & Orita et al. (2010) \\
\hline 3ale & 2.50 & 1460 & $C N S$ & 0.007 & 1.3 & 0.004 & 1.3 & 0.227 & 0.279 & 117 & 15 & Morita et al. (2010) \\
\hline $3 \mathrm{am} 9$ & 2.17 & 2584 & REFMAC & 0.022 & 1.9 & 0.008 & 6.9 & 0.182 & 0.248 & 99 & 12 & Matsumoto et al. (2010) \\
\hline $319 w$ & 1.75 & 695 & REFMAC & 0.018 & 1.6 & 0.007 & 5.6 & 0.212 & 0.239 & 16 & 1 & Roosild et al. (2010) \\
\hline $3 \mathrm{lb} 4$ & 1.56 & 274 & REFMAC & 0.011 & 1.3 & 0.005 & 4.2 & 0.253 & 0.281 & 10 & 0 & Thompson et al. (2010) \\
\hline $31 f 1$ & 2.10 & 686 & PHENIX & 0.007 & 1.0 & 0.002 & 5.2 & 0.207 & 0.266 & 43 & 8 & Zhou et al. (2011) \\
\hline 3lje & 1.75 & 121 & CNS & 0.031 & 2.4 & 0.010 & 3.4 & 0.185 & 0.217 & 14 & 3 & Pizzo et al. (2010) \\
\hline $3 \mathrm{ljq}$ & 1.90 & 570 & CNS & 0.012 & 1.3 & 0.006 & 7.3 & 0.155 & 0.197 & 17 & 1 & Wang \& Guo (2010) \\
\hline $3 l j u$ & 1.70 & 373 & REFMAC & 0.016 & 1.4 & 0.007 & 6.0 & 0.203 & 0.238 & 1 & 0 & Tong et al. (2010) \\
\hline $3 \operatorname{lpf}$ & 2.26 & 1180 & $R E F M A C$ & 0.011 & 2.2 & 0.004 & 8.6 & 0.275 & 0.300 & 241 & 34 & Wallace et al. (2010) \\
\hline 3lre & 2.20 & 589 & REFMAC & 0.020 & 1.7 & 0.006 & 6.4 & 0.231 & 0.278 & 28 & 3 & Peters et al. (2010) \\
\hline $3 \operatorname{lrp}$ & 2.50 & 181 & $C N S$ & 0.006 & 1.2 & 0.004 & 1.2 & 0.197 & 0.263 & 7 & 1 & Cook et al. (2010) \\
\hline $31 \mathrm{lt} 3$ & 2.10 & 404 & $R E F M A C$ & 0.006 & 0.9 & 0.002 & 4.3 & 0.242 & 0.293 & 5 & 0 & Biswas et al. (2010) \\
\hline $3 \mathrm{~m} 0 \mathrm{e}$ & 2.63 & 1729 & PHENIX & 0.010 & 1.2 & 0.003 & 5.3 & 0.216 & 0.250 & 90 & 11 & Chen, Sysoeva et al. (2010) \\
\hline $3 \mathrm{~m} 0 \mathrm{~h}$ & 1.58 & 1685 & CNS & 0.004 & 1.2 & 0.004 & 1.3 & 0.162 & 0.182 & 28 & 6 & Yoshida et al. (2010) \\
\hline $3 \mathrm{~m} 4 \mathrm{z}$ & 1.94 & 309 & REFMAC & 0.012 & 1.2 & 0.004 & 4.9 & 0.177 & 0.202 & 2 & 0 & Heldman et al. (2010) \\
\hline $3 \mathrm{~m} 5 \mathrm{o}$ & 1.60 & 410 & REFMAC & 0.009 & 1.2 & 0.004 & 5.9 & 0.240 & 0.270 & 10 & 3 & Romano et al. (2010) \\
\hline $3 \mathrm{~m} 67$ & 1.80 & 257 & REFMAC & 0.027 & 2.0 & 0.010 & 7.0 & 0.178 & 0.230 & 9 & 0 & Čapkauskaitè et al. (2010) \\
\hline $3 \mathrm{mbv}$ & 2.00 & 222 & REFMAC & 0.016 & 1.4 & 0.007 & 5.1 & 0.270 & 0.282 & 2 & 1 & Borshchevskiy et al. (2010) \\
\hline $3 \mathrm{mfa}$ & 1.63 & 194 & REFMAC & 0.013 & 1.3 & 0.004 & 6.9 & 0.198 & 0.223 & 8 & 0 & Morin et al. (2011) \\
\hline $3 \mathrm{mif}$ & 2.00 & 310 & $R E F M A C$ & 0.009 & 1.1 & 0.002 & 6.1 & 0.261 & 0.279 & 11 & 1 & Chufán et al. (2010) \\
\hline $3 \mathrm{mk} 9$ & 2.08 & 173 & REFMAC & 0.006 & 1.1 & 0.005 & 1.0 & 0.216 & 0.242 & 7 & 0 & Compton et al. (2011) \\
\hline $3 \mathrm{mke}$ & 1.75 & 265 & $R E F M A C$ & 0.012 & 1.3 & 0.005 & 5.8 & 0.158 & 0.188 & 1 & 0 & Ke et al. (2011) \\
\hline $3 m v i$ & 1.60 & 698 & $R E F M A C$ & 0.012 & 1.3 & 0.004 & 5.4 & 0.174 & 0.211 & 10 & 2 & Niu et al. (2010) \\
\hline $3 \mathrm{mxe}$ & 1.85 & 198 & REFMAC & 0.009 & 1.2 & 0.003 & 6.1 & 0.202 & 0.241 & 1 & 0 & Ali et al. (2010) \\
\hline $3 n 2 v$ & 1.55 & 158 & $R E F M A C$ & 0.025 & 1.8 & 0.011 & 6.1 & 0.187 & 0.204 & 1 & 0 & Attolino et al. (2010) \\
\hline 3 nfy & 1.94 & 498 & REFMAC & 0.019 & 1.8 & 0.007 & 6.3 & 0.187 & 0.279 & 23 & 6 & Patterson et al. (2010) \\
\hline 3 nio & 1.60 & 182 & PHENIX & 0.003 & 0.6 & 0.001 & 3.2 & 0.230 & 0.257 & 2 & 1 & Swiecki et al. (2011) \\
\hline $3 n k 4$ & 2.00 & 581 & PHENIX & 0.010 & 1.2 & 0.003 & 5.7 & 0.234 & 0.242 & 14 & 1 & Han et al. (2010) \\
\hline $3 n 16$ & 2.61 & 1545 & PHENIX & 0.007 & 1.2 & 0.002 & 5.2 & 0.238 & 0.252 & 174 & 22 & Paul et al. (2010) \\
\hline $3 \mathrm{~nm} 8$ & 2.00 & 570 & $R E F M A C$ & 0.010 & 1.4 & 0.005 & 2.4 & 0.230 & 0.278 & 53 & 6 & Sendovski et al. (2010) \\
\hline $3 \mathrm{nmi}$ & 2.01 & 636 & REFMAC & 0.008 & 0.9 & 0.014 & 6.9 & 0.207 & 0.245 & 30 & 1 & Radford et al. (2011) \\
\hline 3 nof & 1.60 & 213 & REFMAC & 0.029 & 2.5 & 0.011 & 5.9 & 0.197 & 0.225 & 19 & 3 & Hall et al. (2011) \\
\hline 3 nok & 1.65 & 466 & $R E F M A C$ & 0.023 & 1.9 & 0.009 & 7.0 & 0.199 & 0.243 & 11 & 0 & Carrillo et al. (2010) \\
\hline $3 n v 6$ & 2.20 & 404 & REFMAC & 0.016 & 1.5 & 0.005 & 5.9 & 0.200 & 0.264 & 14 & 2 & Yang et al. (2010) \\
\hline $3 n x g$ & 1.95 & 1291 & $R E F M A C$ & 0.008 & 1.1 & 0.002 & 5.9 & 0.180 & 0.213 & 21 & 0 & Neu et al. (2010) \\
\hline $3 n x p$ & 2.20 & 363 & REFMAC & 0.011 & 1.3 & 0.003 & 6.1 & 0.213 & 0.239 & 11 & 2 & Chen, Pelc et al. (2010) \\
\hline $300 \mathrm{a}$ & 1.77 & 425 & REFMAC & 0.009 & 1.2 & 0.003 & 9.0 & 0.211 & 0.250 & 6 & 1 & $\begin{array}{l}\text { V. Cura, N. Olieric, E.-D. Wang, D. Moras, G. } \\
\text { Eriani \& J. Cavarelli (unpublished work) }\end{array}$ \\
\hline $3 o 3 p$ & 1.70 & 635 & PHENIX & 0.007 & 1.1 & 0.002 & 5.2 & 0.221 & 0.255 & 39 & 4 & Empadinhas et al. (2011) \\
\hline $304 h$ & 1.82 & 2302 & REFMAC & 0.019 & 1.7 & 0.007 & 6.2 & 0.244 & 0.267 & 71 & 19 & Harmat et al. (2011) \\
\hline 3079 & 1.60 & 202 & REFMAC & 0.022 & 1.7 & 0.009 & 5.3 & 0.210 & 0.237 & 4 & 2 & Khan et al. (2010) \\
\hline
\end{tabular}


Table 3 (continued)

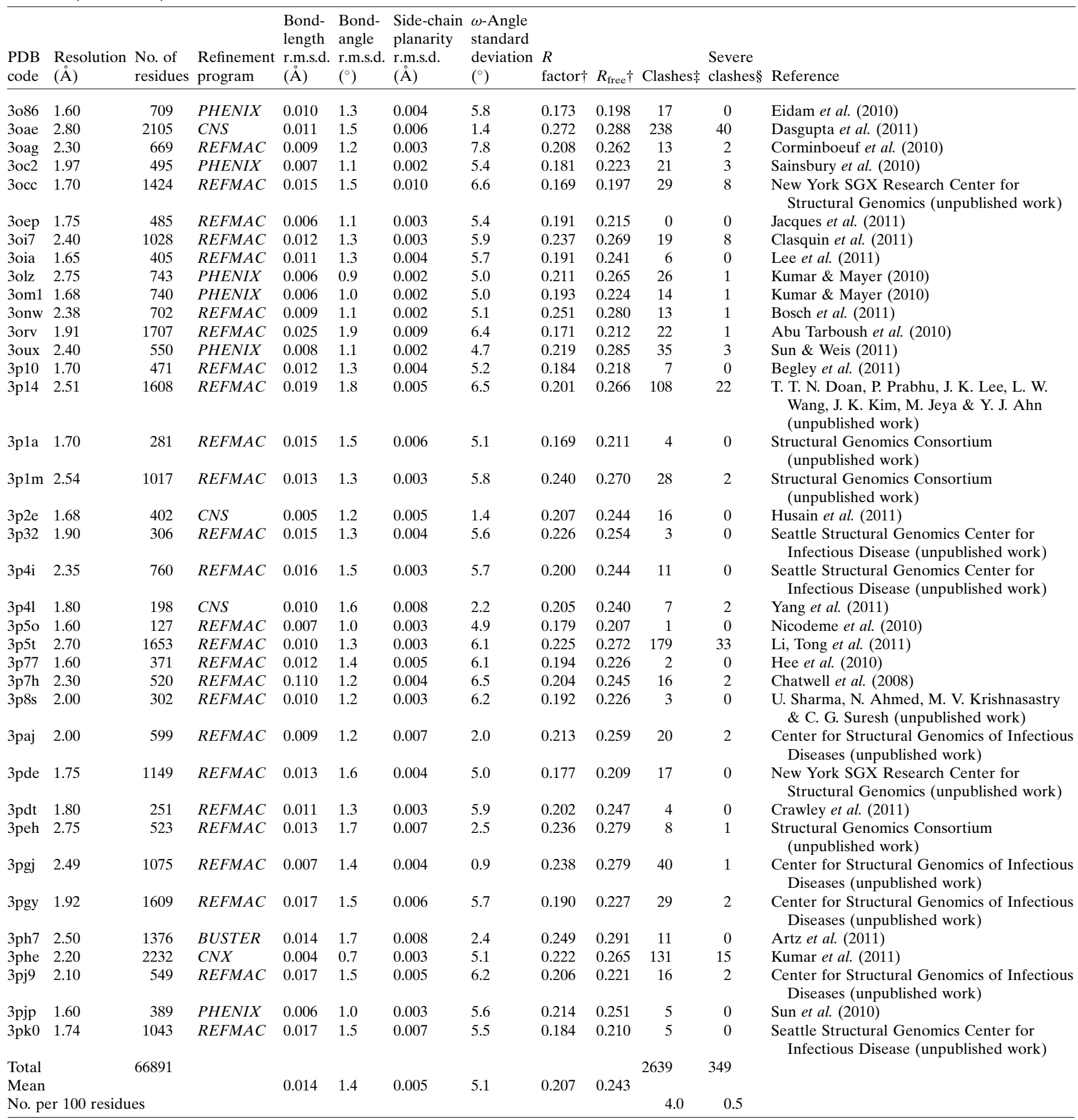

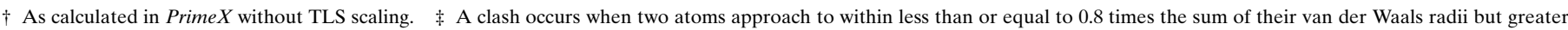

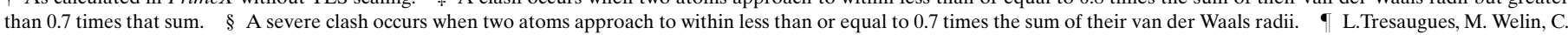

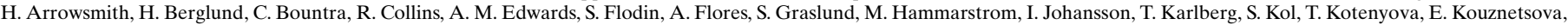
M. Moche, T. Nyman, C. Persson, H. Schuler, P. Schutz, M. I. Siponen, A. G. Thorsell, S. Van der Berg, E. Wahlberg, J. Weigelt \& P. Nordlund (unpublished work).

refinement programs. Unfortunately, refinement results from BUSTER (Bricogne et al., 2011) were found to be relatively rare and only two instances were found in our data set. However, the statistics for these two proteins suggest improved results from this program regarding close contacts. None of the other programs even approached the values of
0.6-0.7 clashes per 100 residues that might be considered a reasonable target considering the results above.

3.3.2. Summary molecular geometry and refinement statistics. Table 5 also provides a summary of the measures of molecular geometry over the three data sets in this study. The average bond-length r.m.s.d. for the Prime $X$-refined 
Table 4

Statistics for structures in the moderate-resolution data set as refined in PrimeX.

\begin{tabular}{|c|c|c|c|c|c|c|c|c|c|c|}
\hline PDB code & Resolution $(\AA)$ & $\begin{array}{l}\text { No. of } \\
\text { residues }\end{array}$ & $\begin{array}{l}\text { Bond-length } \\
\text { r.m.s.d. (A) }\end{array}$ & $\begin{array}{l}\text { Bond-angle } \\
\text { r.m.s.d. }\left({ }^{\circ}\right)\end{array}$ & $\begin{array}{l}\text { Side-chain planarity } \\
\text { r.m.s.d. (§) }\end{array}$ & $\begin{array}{l}\omega \text {-Angle standard } \\
\text { deviation }\left({ }^{\circ}\right)\end{array}$ & $R$ factor & $R_{\text {free }}$ & Clashes & Severe clashes \\
\hline $2 \times 3 k$ & 2.50 & 1145 & 0.019 & 2.3 & 0.005 & 8.0 & 0.212 & 0.267 & 19 & 0 \\
\hline $2 \mathrm{xda}$ & 1.85 & 150 & 0.025 & 2.5 & 0.007 & 6.9 & 0.175 & 0.215 & 3 & 0 \\
\hline $2 \times n 8$ & 1.64 & 409 & 0.022 & 2.2 & 0.005 & 6.6 & 0.170 & 0.221 & 2 & 0 \\
\hline $2 x p p$ & 1.74 & 161 & 0.016 & 1.9 & 0.005 & 5.2 & 0.197 & 0.251 & 3 & 0 \\
\hline $2 \mathrm{xs} 6$ & 2.09 & 166 & 0.019 & 2.0 & 0.004 & 6.8 & 0.195 & 0.263 & 1 & 0 \\
\hline $2 x s n$ & 2.68 & 1341 & 0.017 & 2.0 & 0.005 & 6.6 & 0.229 & 0.275 & 16 & 0 \\
\hline $2 x s q$ & 1.72 & 179 & 0.022 & 2.1 & 0.009 & 6.4 & 0.158 & 0.195 & 0 & 0 \\
\hline $2 \mathrm{xsw}$ & 1.90 & 666 & 0.021 & 2.3 & 0.007 & 7.0 & 0.166 & 0.211 & 5 & 0 \\
\hline $2 \mathrm{xsx}$ & 1.70 & 869 & 0.023 & 2.1 & 0.007 & 6.4 & 0.162 & 0.203 & 4 & 0 \\
\hline $2 \mathrm{xu} 7$ & 1.90 & 752 & 0.020 & 2.2 & 0.006 & 8.0 & 0.186 & 0.235 & 1 & 0 \\
\hline 2xul & 2.20 & 645 & 0.016 & 2.2 & 0.003 & 7.2 & 0.189 & 0.231 & 1 & 0 \\
\hline $2 \mathrm{xvs}$ & 1.80 & 166 & 0.022 & 2.3 & 0.008 & 6.9 & 0.177 & 0.252 & 1 & 0 \\
\hline $2 \mathrm{xvv}$ & 2.40 & 582 & 0.019 & 2.3 & 0.005 & 6.8 & 0.182 & 0.245 & 3 & 0 \\
\hline $2 x x j$ & 1.96 & 1239 & 0.017 & 1.9 & 0.007 & 6.5 & 0.179 & 0.241 & 8 & 0 \\
\hline 3acw & 1.63 & 284 & 0.019 & 2.0 & 0.009 & 5.8 & 0.201 & 0.242 & 1 & 0 \\
\hline 3aey & 1.92 & 698 & 0.021 & 2.2 & 0.008 & 6.3 & 0.171 & 0.204 & 12 & 0 \\
\hline 3ajx & 1.60 & 828 & 0.022 & 2.2 & 0.006 & 5.7 & 0.178 & 0.211 & 1 & 0 \\
\hline 3ale & 2.50 & 1460 & 0.015 & 2.1 & 0.004 & 7.5 & 0.233 & 0.272 & 16 & 0 \\
\hline $3 \mathrm{am} 9$ & 2.17 & 2584 & 0.017 & 2.1 & 0.005 & 7.1 & 0.175 & 0.241 & 23 & 0 \\
\hline $319 w$ & 1.75 & 695 & 0.023 & 2.4 & 0.009 & 6.5 & 0.199 & 0.233 & 3 & 0 \\
\hline 3lb4 & 1.56 & 274 & 0.018 & 2.3 & 0.012 & 5.1 & 0.244 & 0.277 & 1 & 0 \\
\hline 3lfl & 2.10 & 686 & 0.017 & 1.9 & 0.003 & 8.5 & 0.202 & 0.269 & 8 & 0 \\
\hline 3lje & 1.75 & 121 & 0.025 & 2.4 & 0.006 & 6.5 & 0.175 & 0.211 & 1 & 0 \\
\hline $3 l j q$ & 1.90 & 570 & 0.020 & 2.2 & 0.006 & 7.2 & 0.144 & 0.200 & 5 & 0 \\
\hline 3lju & 1.70 & 373 & 0.021 & 2.2 & 0.007 & 6.9 & 0.192 & 0.237 & 1 & 0 \\
\hline 3lpf & 2.26 & 1180 & 0.017 & 2.3 & 0.005 & 10.2 & 0.280 & 0.325 & 30 & 1 \\
\hline 3lre & 2.20 & 589 & 0.016 & 2.1 & 0.005 & 7.0 & 0.218 & 0.273 & 2 & 0 \\
\hline 31 rp & 2.50 & 181 & 0.017 & 2.2 & 0.004 & 7.1 & 0.184 & 0.252 & 3 & 0 \\
\hline $31 \mathrm{t} 3$ & 2.10 & 404 & 0.019 & 2.4 & 0.005 & 7.5 & 0.188 & 0.282 & 2 & 0 \\
\hline $3 \mathrm{~m} 0 \mathrm{e}$ & 2.63 & 1729 & 0.015 & 1.9 & 0.004 & 6.8 & 0.236 & 0.273 & 18 & 0 \\
\hline $3 \mathrm{~m} 0 \mathrm{~h}$ & 1.58 & 1685 & 0.022 & 2.2 & 0.008 & 5.8 & 0.144 & 0.178 & 9 & 0 \\
\hline $3 \mathrm{~m} 4 \mathrm{z}$ & 1.94 & 309 & 0.020 & 2.1 & 0.007 & 6.1 & 0.160 & 0.203 & 0 & 0 \\
\hline $3 \mathrm{~m} 5 \mathrm{o}$ & 1.60 & 410 & 0.015 & 2.0 & 0.007 & 7.0 & 0.206 & 0.247 & 2 & 2 \\
\hline $3 \mathrm{~m} 67$ & 1.80 & 257 & 0.026 & 2.6 & 0.005 & 7.9 & 0.168 & 0.226 & 4 & 0 \\
\hline $3 \mathrm{mbv}$ & 2.00 & 222 & 0.017 & 1.8 & 0.006 & 5.9 & 0.248 & 0.292 & 1 & 0 \\
\hline $3 \mathrm{mfa}$ & 1.63 & 194 & 0.021 & 2.3 & 0.012 & 8.6 & 0.181 & 0.225 & 1 & 0 \\
\hline $3 \mathrm{mif}$ & 2.00 & 310 & 0.021 & 2.4 & 0.008 & 9.3 & 0.194 & 0.242 & 3 & 0 \\
\hline $3 \mathrm{mk} 9$ & 2.08 & 173 & 0.017 & 1.9 & 0.006 & 6.8 & 0.186 & 0.246 & 2 & 0 \\
\hline $3 \mathrm{mke}$ & 1.75 & 265 & 0.020 & 2.1 & 0.010 & 6.8 & 0.148 & 0.191 & 0 & 0 \\
\hline $3 \mathrm{mvi}$ & 1.60 & 698 & 0.023 & 2.2 & 0.008 & 6.3 & 0.162 & 0.205 & 3 & 0 \\
\hline $3 \mathrm{mxe}$ & 1.85 & 198 & 0.019 & 2.3 & 0.005 & 7.7 & 0.183 & 0.251 & 0 & 0 \\
\hline $3 \mathrm{n} 2 \mathrm{v}$ & 1.55 & 158 & 0.023 & 2.4 & 0.008 & 7.2 & 0.178 & 0.227 & 0 & 0 \\
\hline 3nfy & 1.94 & 498 & 0.017 & 2.1 & 0.004 & 6.9 & 0.181 & 0.259 & 6 & 0 \\
\hline $3 \mathrm{ni0}$ & 1.60 & 182 & 0.017 & 1.9 & 0.003 & 5.2 & 0.213 & 0.254 & 0 & 0 \\
\hline 3nk4 & 2.00 & 581 & 0.021 & 2.5 & 0.006 & 7.8 & 0.217 & 0.247 & 7 & 0 \\
\hline $3 \mathrm{n} 16$ & 2.61 & 1545 & 0.016 & 2.4 & 0.005 & 7.8 & 0.225 & 0.273 & 23 & 2 \\
\hline $3 \mathrm{~nm} 8$ & 2.00 & 570 & 0.018 & 2.2 & 0.007 & 7.4 & 0.191 & 0.262 & 2 & 0 \\
\hline $3 \mathrm{nmi}$ & 2.01 & 636 & 0.023 & 2.4 & 0.005 & 6.8 & 0.198 & 0.244 & 9 & 1 \\
\hline 3 nof & 1.60 & 213 & 0.021 & 2.4 & 0.010 & 6.5 & 0.186 & 0.216 & 2 & 0 \\
\hline 3nok & 1.65 & 466 & 0.016 & 2.0 & 0.005 & 7.4 & 0.198 & 0.243 & 4 & 0 \\
\hline 3nv6 & 2.20 & 404 & 0.015 & 2.0 & 0.004 & 6.6 & 0.196 & 0.260 & 0 & 0 \\
\hline $3 n \times g$ & 1.95 & 1291 & 0.018 & 2.2 & 0.006 & 7.5 & 0.166 & 0.213 & 8 & 0 \\
\hline $3 n x p$ & 2.20 & 363 & 0.015 & 2.1 & 0.005 & 8.1 & 0.196 & 0.238 & 9 & 0 \\
\hline $300 a$ & 1.77 & 425 & 0.019 & 2.2 & 0.007 & 7.2 & 0.187 & 0.248 & 2 & 2 \\
\hline $3 o 3 p$ & 1.70 & 635 & 0.020 & 2.5 & 0.006 & 8.2 & 0.216 & 0.251 & 14 & 0 \\
\hline $304 \mathrm{~h}$ & 1.82 & 2302 & 0.015 & 2.2 & 0.005 & 6.5 & 0.216 & 0.270 & 16 & 2 \\
\hline 3079 & 1.60 & 202 & 0.024 & 2.5 & 0.012 & 11.1 & 0.192 & 0.239 & 2 & 1 \\
\hline 3086 & 1.60 & 709 & 0.021 & 2.1 & 0.007 & 6.8 & 0.167 & 0.196 & 4 & 0 \\
\hline 3oae & 2.80 & 2105 & 0.017 & 2.5 & 0.005 & 9.4 & 0.237 & 0.294 & 39 & 0 \\
\hline 3oag & 2.30 & 669 & 0.015 & 2.1 & 0.005 & 8.3 & 0.210 & 0.261 & 1 & 0 \\
\hline $30 c 2$ & 1.97 & 495 & 0.019 & 2.3 & 0.007 & 7.5 & 0.171 & 0.226 & 5 & 1 \\
\hline 3 occ & 1.70 & 1424 & 0.021 & 2.1 & 0.007 & 7.1 & 0.156 & 0.192 & 15 & 5 \\
\hline 3oep & 1.75 & 485 & 0.020 & 2.2 & 0.008 & 6.5 & 0.168 & 0.210 & 4 & 0 \\
\hline 3oi7 & 2.40 & 1028 & 0.015 & 1.9 & 0.005 & 6.9 & 0.241 & 0.280 & 7 & 0 \\
\hline 3oia & 1.65 & 405 & 0.022 & 2.3 & 0.008 & 7.0 & 0.171 & 0.237 & 5 & 0 \\
\hline $3 \mathrm{olz}$ & 2.75 & 743 & 0.014 & 2.0 & 0.003 & 6.8 & 0.238 & 0.264 & 10 & 0 \\
\hline 3om1 & 1.68 & 740 & 0.022 & 2.4 & 0.007 & 6.9 & 0.183 & 0.223 & 6 & 0 \\
\hline 3onw & 2.38 & 702 & 0.018 & 2.2 & 0.005 & 7.4 & 0.225 & 0.263 & 6 & 0 \\
\hline 3orv & 1.91 & 1707 & 0.017 & 2.0 & 0.006 & 7.2 & 0.155 & 0.207 & 10 & 0 \\
\hline 3oux & 2.40 & 550 & 0.017 & 2.2 & 0.004 & 6.4 & 0.220 & 0.267 & 8 & 0 \\
\hline
\end{tabular}


Table 4 (continued)

\begin{tabular}{|c|c|c|c|c|c|c|c|c|c|c|}
\hline PDB code & Resolution ( & $\begin{array}{l}\text { No. of } \\
\text { residues }\end{array}$ & $\begin{array}{l}\text { Bond-length } \\
\text { r.m.s.d. (A) }\end{array}$ & $\begin{array}{l}\text { Bond-angle } \\
\text { r.m.s.d. }\left({ }^{\circ}\right)\end{array}$ & $\begin{array}{l}\text { Side-chain planarity } \\
\text { r.m.s.d. (̊) }\end{array}$ & $\begin{array}{l}\omega \text {-Angle standard } \\
\text { deviation }\left({ }^{\circ}\right)\end{array}$ & $R$ factor & $R_{\text {free }}$ & Clashes & Severe clashes \\
\hline $3 \mathrm{p} 10$ & 1.70 & 471 & 0.018 & 2.1 & 0.006 & 6.3 & 0.173 & 0.222 & 4 & 0 \\
\hline $3 \mathrm{p} 14$ & 2.51 & 1608 & 0.015 & 2.1 & 0.005 & 7.1 & 0.211 & 0.259 & 21 & 5 \\
\hline $3 \mathrm{p} 1 \mathrm{a}$ & 1.70 & 281 & 0.023 & 2.0 & 0.009 & 5.8 & 0.162 & 0.212 & 2 & 0 \\
\hline $3 \mathrm{p} 1 \mathrm{~m}$ & 2.54 & 1017 & 0.013 & 2.1 & 0.002 & 6.9 & 0.231 & 0.273 & 8 & 0 \\
\hline $3 \mathrm{p} 2 \mathrm{e}$ & 1.68 & 402 & 0.021 & 2.2 & 0.008 & 6.6 & 0.186 & 0.234 & 3 & 0 \\
\hline 3 p32 & 1.90 & 306 & 0.024 & 2.3 & 0.005 & 7.3 & 0.204 & 0.252 & 3 & 0 \\
\hline $3 \mathrm{p} 4 \mathrm{i}$ & 2.35 & 760 & 0.019 & 2.1 & 0.004 & 7.0 & 0.195 & 0.241 & 2 & 0 \\
\hline $3 \mathrm{p} 41$ & 1.80 & 198 & 0.018 & 2.0 & 0.008 & 7.2 & 0.200 & 0.248 & 1 & 0 \\
\hline $3 \mathrm{p} 5 \mathrm{o}$ & 1.60 & 127 & 0.023 & 2.1 & 0.008 & 6.1 & 0.156 & 0.209 & 1 & 0 \\
\hline $3 \mathrm{p} 5 \mathrm{t}$ & 2.70 & 1653 & 0.016 & 2.0 & 0.004 & 7.4 & 0.230 & 0.285 & 4 & 0 \\
\hline $3 \mathrm{p} 77$ & 1.60 & 371 & 0.021 & 2.3 & 0.008 & 6.8 & 0.173 & 0.221 & 2 & 0 \\
\hline $3 \mathrm{p} 7 \mathrm{~h}$ & 2.30 & 520 & 0.016 & 2.0 & 0.005 & 8.1 & 0.200 & 0.244 & 2 & 0 \\
\hline $3 \mathrm{p} 8 \mathrm{~s}$ & 2.00 & 302 & 0.018 & 2.2 & 0.006 & 7.7 & 0.165 & 0.221 & 2 & 0 \\
\hline 3paj & 2.00 & 599 & 0.018 & 2.2 & 0.006 & 6.2 & 0.179 & 0.251 & 6 & 0 \\
\hline 3 pde & 1.75 & 1149 & 0.020 & 2.1 & 0.006 & 6.1 & 0.169 & 0.212 & 8 & 0 \\
\hline $3 \mathrm{pdt}$ & 1.80 & 251 & 0.018 & 2.0 & 0.005 & 7.6 & 0.182 & 0.237 & 2 & 0 \\
\hline 3 peh & 2.75 & 523 & 0.019 & 2.6 & 0.006 & 8.4 & 0.234 & 0.288 & 10 & 0 \\
\hline $3 \mathrm{pgj}$ & 2.49 & 1075 & 0.014 & 1.9 & 0.003 & 7.0 & 0.249 & 0.287 & 3 & 0 \\
\hline 3 pgy & 1.92 & 1609 & 0.017 & 2.0 & 0.005 & 6.7 & 0.173 & 0.225 & 8 & 0 \\
\hline $3 \mathrm{ph} 7$ & 2.50 & 1376 & 0.016 & 2.0 & 0.006 & 6.4 & 0.248 & 0.304 & 8 & 0 \\
\hline 3 phe & 2.20 & 2232 & 0.016 & 2.0 & 0.004 & 7.7 & 0.213 & 0.255 & 11 & 1 \\
\hline 3pj9 & 2.10 & 549 & 0.021 & 2.2 & 0.004 & 7.3 & 0.185 & 0.220 & 10 & 0 \\
\hline 3pjp & 1.60 & 389 & 0.022 & 2.4 & 0.008 & 7.7 & 0.203 & 0.253 & 2 & 0 \\
\hline $3 \mathrm{pk} 0$ & 1.74 & 1043 & 0.023 & 2.3 & 0.007 & 6.2 & 0.160 & 0.207 & 7 & 0 \\
\hline Total & & 66891 & & & & & & & 573 & 23 \\
\hline Mean & 1.99 & & 0.019 & 2.2 & 0.006 & 7.1 & 0.193 & 0.242 & & \\
\hline No. per 100 residues & & & & & & & & & 0.9 & 0.03 \\
\hline
\end{tabular}

proteins was $0.019 \AA$, compared with $0.015 \AA$ for the original data set. The r.m.s. $Z$ scores (Spronk et al., 2004) for bond lengths changed from an average value of $0.56(0.15-1.27)$ as deposited to an average value of $0.89(0.65-1.24)$ after PrimeX refinement. The ultrahigh-resolution set had a bond-length r.m.s.d. of $0.021 \AA$ and a mean bond-length r.m.s. $Z$ score of $0.87(0.49-1.23)$, values that are very similar to those of the Prime $X$-refined structures. Individual bond-length r.m.s. $Z$ scores are available as Supplementary Material. ${ }^{\mathbf{1}}$.

Table 5 also allows comparison among the four programs originally used to refine the moderate-resolution data set. PHENIX and CNS clearly restrained bond lengths more tightly than did PrimeX. The bond-length r.m.s.d. for the $R E F M A C$-refined set was not very different from the PrimeXrefined set.

The average bond-angle r.m.s.d. for Prime $X$ was $2.2^{\circ}$, which is somewhat larger than the average value of $1.4^{\circ}$ over the original data set. The r.m.s. $Z$ scores for bond angles changed from an average value of $0.71(0.37-1.25)$ as deposited to an average value of 1.17 (1.00-1.49) after Prime $X$ refinement. The average bond-angle r.m.s.d. in the ultrahigh-resolution set was $2.5^{\circ}$, which is greater than that produced by any of the other refinement programs, but closest to the value for Prime $X$. The r.m.s. $Z$ score for bond angles in the ultrahighresolution set was $1.12(0.79-1.46)$, which is also similar to that

\footnotetext{
${ }^{\mathbf{1}}$ Supplementary material has been deposited in the IUCr electronic archive (Reference: RR5017). Services for accessing this material are described at the back of the journal.
}

of the Prime $X$-refined structures. Individual bond-angle r.m.s. $Z$ scores are available in the Supplementary Material ${ }^{\mathbf{1}}$.

The average side-chain group planarity r.m.s.d. for Prime $X$ was $0.006 \AA$, which is a fairly typical value for this quantity among the refinement programs. Side-chain planarity deviations were all small and not very different between these two data sets, nor did they differ much by refinement program (Table 5).

The average $\omega$-angle standard deviation for PrimeX, $7.1^{\circ}$, was larger than for any of the refinement programs used to produce the original moderate-resolution data set, but compared well with the value of $6.4^{\circ}$ obtained for the ultrahighresolution set (Table 5). The values among all the refinement programs could be described as a range of values from $4.8^{\circ}$ to $5.7^{\circ}$, with two outliers near $2^{\circ}$ for BUSTER and $C N S / C N X$. The number of examples of $B U S T E R$-refined proteins was too small to draw a conclusion. However, $C N S$ and $C N X$ clearly often restrain the $\omega$ angle very tightly. This issue was originally observed by Priestle (2003). Note that the overall average for the $\omega$ angles did not represent the situation well, since two of the 12 structures in the $C N S / C N X$ subgroup had standard deviations in the normal range (Table 3). These two uncharacteristic $C N S / C N X$ structures indicate that at least a few users of $C N S / C N X$ have taken steps to loosen these peptidebond planarity restraints. Ten of the 12 members of the CNS/ $C N X$ subgroup had standard deviations for $\omega$ of $1.5^{\circ}$ or less, implying flattened peptide bonds throughout these crystal structures. The $\omega$-angle standard deviation did not vary much among the other refinement programs. The average value for REFMAC did not stand out as the one from CNS/CNX does. 
Table 5

Summary of geometry and clash statistics.

\begin{tabular}{|c|c|c|c|c|c|c|c|}
\hline Structure set & $\begin{array}{l}\text { No. of } \\
\text { structures }\end{array}$ & $\begin{array}{l}\text { Bond-length } \\
\text { r.m.s.d. }(\AA)\end{array}$ & $\begin{array}{l}\text { Bond-angle } \\
\text { r.m.s.d. }\left({ }^{\circ}\right)\end{array}$ & $\begin{array}{l}\text { Side-chain planarity } \\
\text { r.m.s.d. (A) }\end{array}$ & $\begin{array}{l}\omega \text {-Angle standard } \\
\text { deviation }\left({ }^{\circ}\right)\end{array}$ & $\begin{array}{l}\text { Clashes per } \\
100 \text { residues }\end{array}$ & $\begin{array}{l}\text { Severe clashes } \\
\text { per } 100 \text { residues }\end{array}$ \\
\hline Ultrahigh-resolution set & 18 & 0.021 & 2.5 & 0.011 & 6.4 & $0.6 \dagger$ & $0.03 \dagger$ \\
\hline $\begin{array}{l}\text { Moderate-resolution set + additional } \\
\text { Prime } X \text { refinement }\end{array}$ & 94 & 0.019 & 2.2 & 0.006 & 7.1 & $0.7 \ddagger$ & $0.03 \ddagger$ \\
\hline Moderate-resolution set as deposited & 94 & 0.015 & 1.4 & 0.005 & 5.1 & 4.0 & 0.5 \\
\hline BUSTER-refined subset & 2 & 0.014 & 1.7 & 0.008 & 2.6 & 0.9 & 0.07 \\
\hline$C N S / C N X$-refined subset & 12 & 0.009 & 1.3 & 0.005 & 2.3 & 5.9 & 0.8 \\
\hline
\end{tabular}

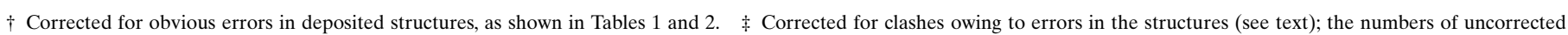
clashes and severe clashes per 100 residues are 0.9 and 0.03 , respectively.

At the same time, some users of REFMAC did very tightly restrain peptide bonds. The lowest standard deviation for $\omega$ was not from among the $C N S / C N X$-refined structures, but instead was produced by $R E F M A C$ (3pgj; $\left.0.9^{\circ}\right)$.

Changes in overall structure quality owing to PrimeX refinement, as judged by the Ramachandran $Z$ scores (Spronk et al., 2004), were generally small. Only one change was noted as significant by the program WHAT_CHECK. This change was from an original value of -3.16 for the protein $3 \mathrm{nl} 6$ as originally deposited to a value of -2.11 after Prime $X$ refinement. The mean Ramachandran $Z$ score changed from -0.37 (range -3.16 to +3.69 ) as originally deposited to -0.51 (range -2.56 to +3.05$)$ after Prime $X$ refinement. Individual Ramachandran $Z$ scores before and after Prime $X$ refinement are shown in the Supplementary Material.

The average $R_{\text {free }}$ value over the moderate-resolution set was the same with or without the additional Prime $X$ all-atom refinement ( 0.243 versus 0.242 ; Tables 2 and 3$)$. The average for all working $R$ values was somewhat lower for the Prime $X$ refined structures $(0.193)$ versus the average from the original structures (0.207).

\subsection{Additional benefits from all-atom refinement}

The advantages of all-atom refinement of structures at moderate resolution extend well beyond the prevention and remediation of clashes. A few examples from the Prime $X$ refinements in this study illustrate how a detailed description of nonbonded contacts influenced and improved the results of refinement.

3.4.1. Repositioning of a methionine methyl group. Fig. 1 provides an example in which all-atom refinement used in Prime $X$ led to a significant improvement in the structural model. In PDB entry 3phe, clashes of the $\mathrm{C}^{\varepsilon}$ and associated $\mathrm{H}$ atoms of MetC187 with atoms from LeuC293 and TyrC296 suggest that at least one of these residues is in the wrong position. PrimeX refinement using the 'polish' workflow moved the methyl group as shown in Fig. 1 without manual intervention. The $2 F_{\mathrm{o}}-F_{\mathrm{c}}$ electron-density map as shown did not give any clear indication of the correct position for this methyl group. However, the position as deposited was unfavourable and unlikely to be correct as judged from the observed clashes. The new position for the methionine methyl group relieved all close contacts and was confirmed by a small pair of negative and positive difference features in an $F_{\mathrm{o}}-F_{\mathrm{c}}$ map (result not shown). The refinement program $C N X$ did not correct this situation. A reasonable hypothesis for why it did not do so is that the interactions between the methionine methyl group and the other two residues, as represented through a united-atom model in $C N X$, were not unfavorable enough to cause a change in the positions of these atoms.

3.4.2. Backbone change to relieve clash leads to additional ligand hydrogen bonds. In PDB entry 3nl6, atoms in the side chain of ValC209 clash with the side chain of ValC15 (Fig. 2). In producing the all-atom model derived from this structure through energy minimization, these interactions were sufficiently repulsive that the bond angles around $\mathrm{C}^{\beta}$ of ValC15 were distorted rather than allowing atoms to overlap to such an extreme extent. The close contact was relieved during Prime $X$ refinement using the 'polish' workflow by motion of residues C209 and C210 away from residue C15 and towards the bound thiamine phosphate (TPS), as shown in Fig. 2. This side-chain motion occurred with a change in the conformation of the main chain for residue C209. This change in the backbone position and a few other more subtle atomic shifts provided multiple additional hydrogen-bond interactions between the protein and the TPS molecule, a difference that has potentially major implications for the understanding of TPS binding. This large structural change during refinement was probably related to the resolution of the strain of close contacts in the model, but electrostatic gradients or other influences during refinement could also play a role. Assuming that the program was used as intended and in the absence of any indication to the contrary (Paul et al., 2010), phenix.refine seems to have tolerated these severe implied all-atom clashes during refinement.

3.4.3. Refinement of two side-chain positions provides a new view of ADP binding. In its original position in PDB entry 3pdt, as refined in REFMAC, a clash occurred between GlnA758 and PheA720 in the all-atom structure (Fig. 3). The change in structure after Prime $X$ refinement using the 'polish' workflow is hypothesized to have occurred through the following chain of events. The movement of the GlnA758 side chain was first driven by relief of this clash. Concurrently, the LysA722 side chain was moved towards the phosphate group of the ADP molecule under the influence of both the force 
field and electron-density gradients, which also required the motion of the glutamine to avoid the formation of a clash with the lysine. Whatever the causes, the result was a large coordinated movement of the lysine and glutamine side chains which was dramatic both in terms of the extent of the motion of the glutamine side chain and in the difference in the key interactions observed for the binding of ADP to this protein.

The molecular model as originally deposited contains several side chains, including GlnA758, that are misfitted and thus this structure might be considered by some to be a poor candidate for automated refinement. In this alternate view of the situation shown in Fig. 3, residue GlnA758 is positioned outside of the anticipated radius of convergence for refinement. However, one conclusion is clear: REFMAC was tolerant of the implied clash as described above either because it was designed to behave so or because a decision by the users (Crawley et al., 2011) caused REFMAC to behave in this way. Prime $X$ all-atom refinement is not tolerant of such interactions because of the highly unfavorable energetics calculated for such an interaction and it does not allow users to modify its behavior to tolerate such interactions without extraordinary efforts. Even when considered in this context, the ability of the automated PrimeX polish workflow to improve the model in the manner described in Fig. 3 is encouraging.

\section{Discussion}

\subsection{Summary geometry statistics for Prime $X$ and other refinement programs}

While this study was primarily focused on close nonbonded contacts and refinement using an all-atom model, other issues regarding molecular geometry were also of interest and might best be discussed first. Only moderate-resolution structures deposited and released in 2010 were used in this study to ensure that the results reflected current practices in protein crystallography, especially with respect to geometric restraints.

Use of the OPLS all-atom force field in PrimeX $X$ produced reasonable results with respect to summary geometry that were in line with other programs in terms of bond-length deviation and side-chain group planarity (Table 5). The results from the two other summary geometry descriptors monitored here deserve additional comment.

The average of the bond-angle r.m.s.d.s for Prime $X\left(2.2^{\circ}\right)$ is greater than for any of the other programs that created the original moderate-resolution structure set (range 1.1-1.7 ${ }^{\circ}$; Table 5). However, the observation from the ultrahighresolution data set of an average bond-angle r.m.s.d. of $2.5^{\circ}$ (range $1.4-3.1^{\circ}$; Table 1) clearly suggests that this r.m.s.d. is reasonable.

Over-restraint of $\omega$ angles in $C N S / C N X$ has been recognized for several years (Priestle, 2003). Considering the time that has passed since this publication, the number of structures from BUSTER, CNS/CNX and REFMAC observed with very low deviation of $\omega$ angles is hard to understand. While overrestraint is easy to recognize, the correct degree of variability is less easy to define. MacArthur \& Thornton (1996) suggested from their study of proteins and small polypeptides that a standard deviation of $6^{\circ}$ is appropriate.

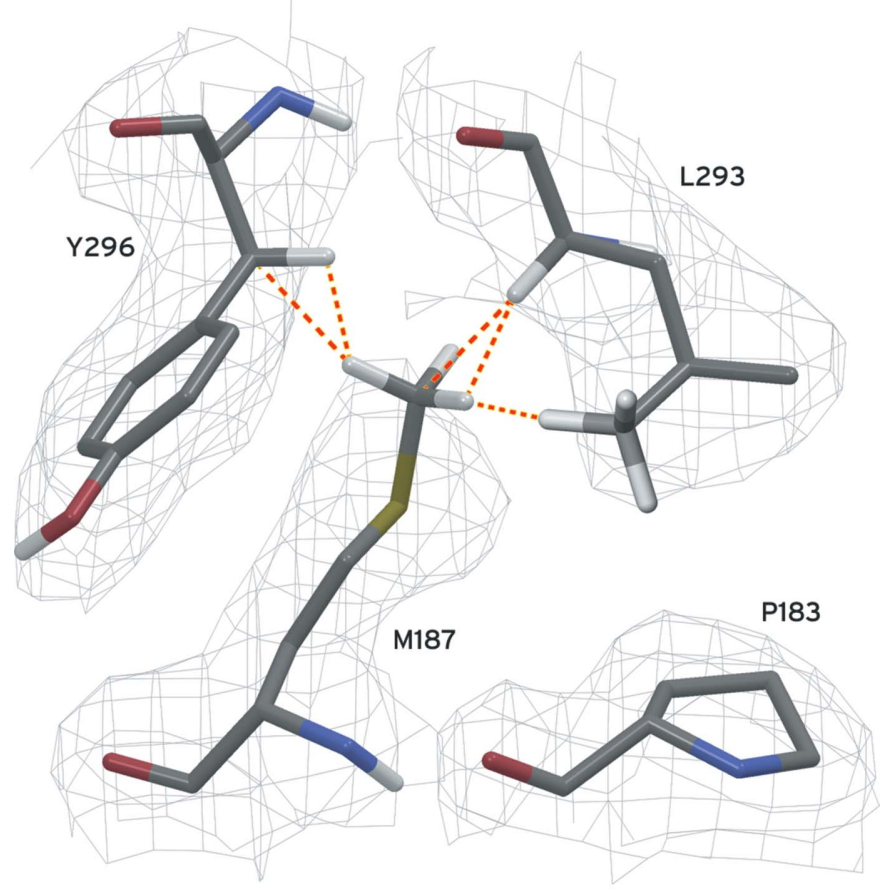

(a)

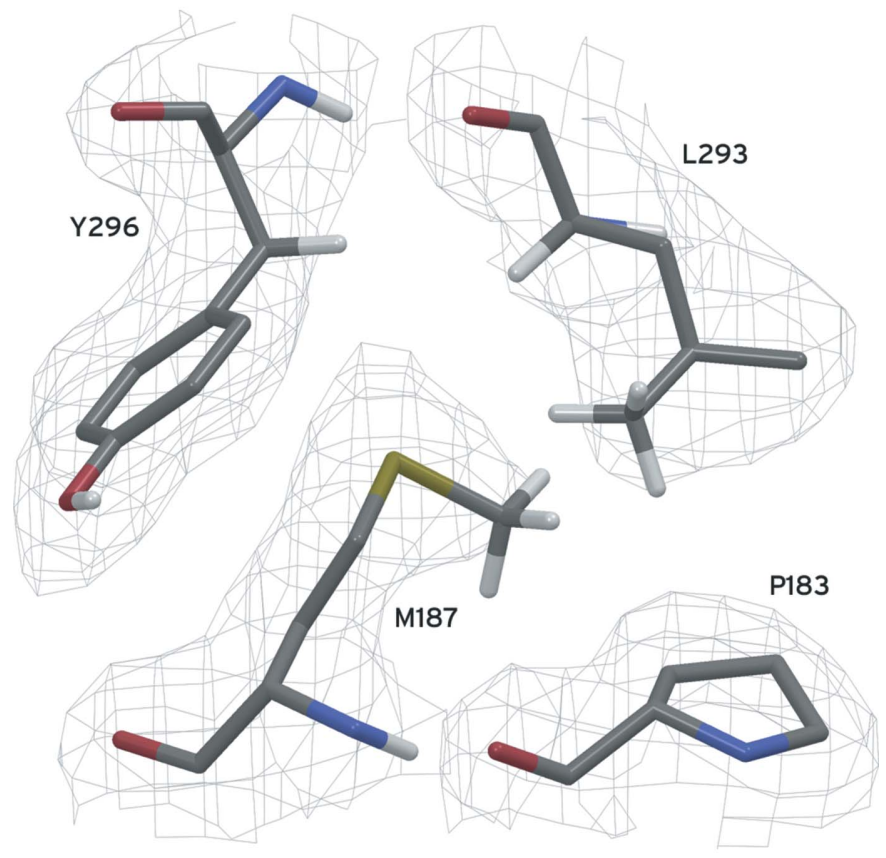

(b)

Figure 1

MetC187 in PDB entry 3phe is shown in (a) as originally refined in $C N X$, with only a selection of $\mathrm{H}$ atoms added for clarity. Clashes between the terminal methyl group of the methionine and two other residues are shown as orange dashed lines. These close interactions were tolerated during the original refinement as a united-atom model. In $(b)$ the location of the methyl group after PrimeX $X$ refinement is shown, where no clashes involving the methyl group were observed. The electron-density grid for this region is contoured at $1.0 \sigma$ from a $2 F_{\mathrm{o}}-F_{\mathrm{c}}$ composite OMIT map. 
Forcing bond angles or torsion angles toward idealized values does carry a risk. If an interaction such as a nonbonded repulsion has driven a particular torsion or bond angle away from the idealized value, restraining it to be closer to the idealized value must make that other interaction more unfavorable. Thus, the result of strictly enforcing these ideal

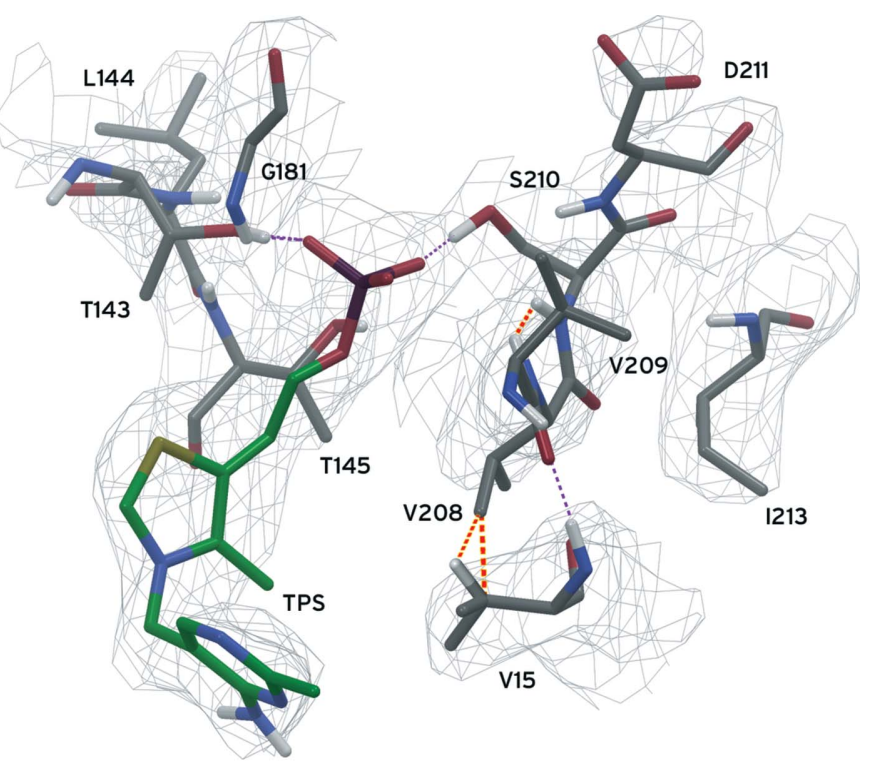

(a)

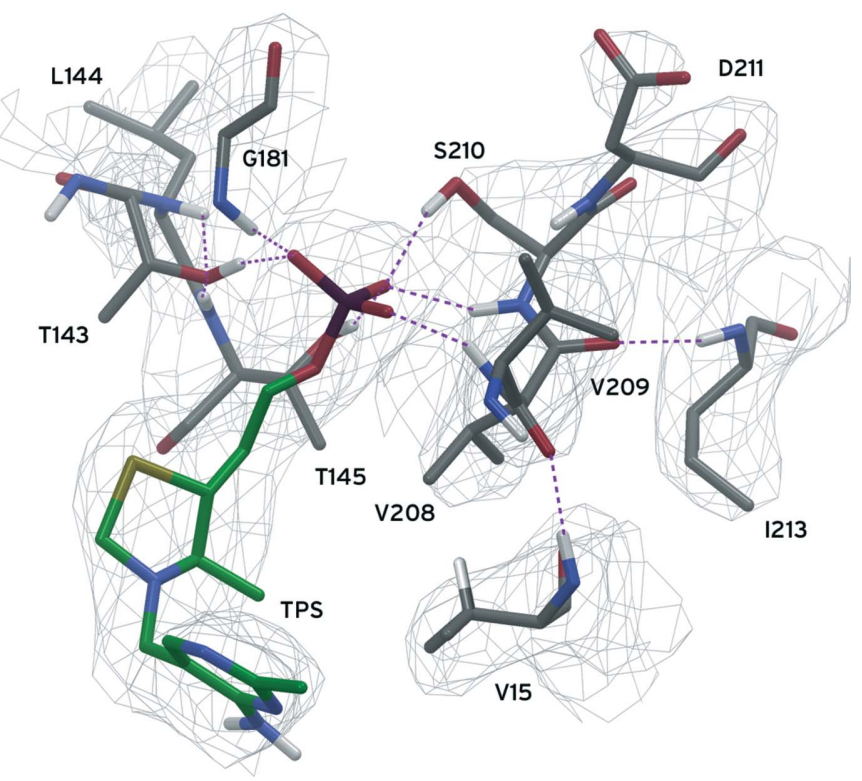

(b)

Figure 2

The region near ValC209 in PDB entry 3nl6 is shown in (a) as originally produced with phenix.refine. All $\mathrm{H}$ atoms were added to this model and their positions were minimized while holding non-H atoms in fixed positions, but only some of these $\mathrm{H}$ atoms are shown for clarity. The extremely close contacts between the $\mathrm{H}$ atom attached to $\mathrm{C}^{\beta}$ of ValC15 and atoms of the ValC209 side chain (orange dashed lines) distorted the bond angles around $\mathrm{C}^{\beta}$. The coordinates of residues C209 and C210 changed after Prime $X$ refinement as shown in $(b)$, with a shift in the backbone conformation, relieving the close contacts and resulting in multiple additional hydrogen bonds to the ligand (purple dashed lines). The electron-density grid for this region is contoured at $1.0 \sigma$ from a $2 F_{\mathrm{o}}-F_{\mathrm{c}}$ composite OMIT map. values could be an increase in the number or severity of clashes.

That the same $R_{\text {free }}$ was obtained with our force-field-based restraints as with Engh and Huber restraints suggests that these restraints are reasonably consistent with protein crystal structures. However, taken together, the decrease in the average $R$ factor $\left(R_{\text {work }}\right)$, the relatively large r.m.s.d. for bond angles compared with the deposited structures and the

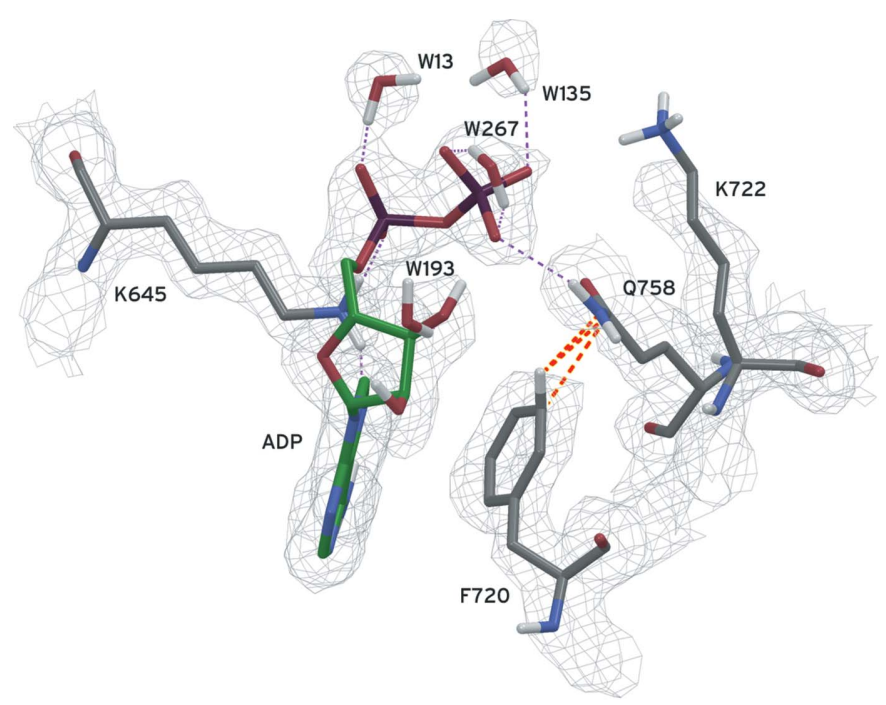

(a)

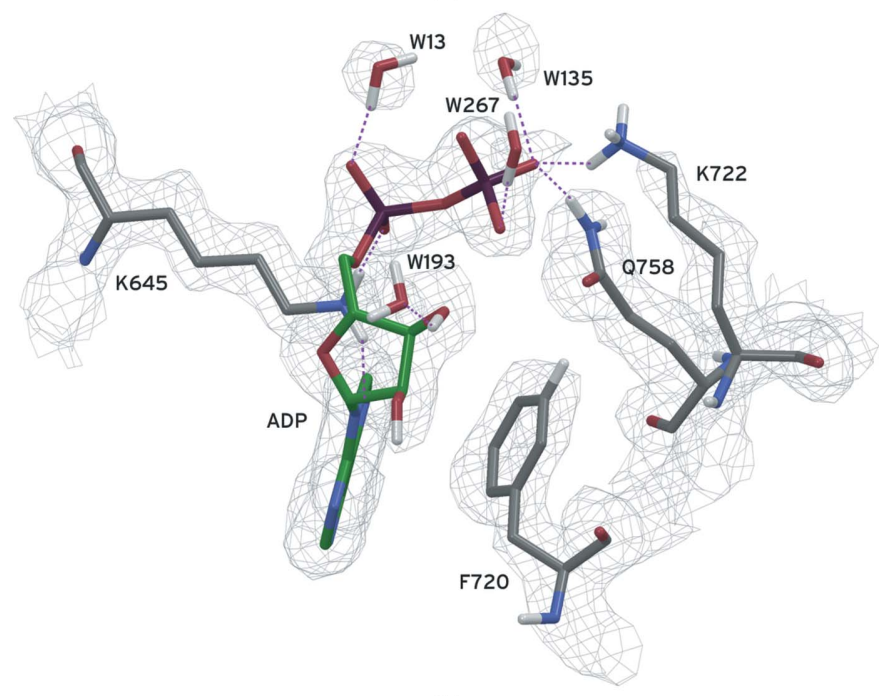

(b)

Figure 3

The region near ADP A811 in PDB entry 3pdt is shown in $(a)$ as originally refined in REFMAC. All $\mathrm{H}$ atoms were added to this model and their positions were minimized while holding non-H atoms fixed, but only some of these $\mathrm{H}$ atoms are shown for clarity. Multiple clashes between the misplaced residue GlnA758 and PheA720 were apparently tolerated in the REFMAC refinement. The close contacts (orange dashed lines) were so severe that the energy minimization distorted the planarity of the aromatic system rather than allowing the higher energy interpenetration of atoms. The position of these two residues after refinement with PrimeX is shown in $(b)$. In order to relieve the strain of the clash, the LysA722 side chain moved toward the ligand with a coordinated motion of the glutamine side chain into its correct position in strong electron density below the Lys residue. Hydrogen bonds are shown as purple dashed lines. The electron-density grid for this region is contoured at $1.0 \sigma$ from a $2 F_{\mathrm{o}}-F_{\mathrm{c}}$ composite OMIT map. 
somewhat larger standard deviation for the $\omega$ angle above the optimal value conceived by MacArthur \& Thornton (1996) could be interpreted as evidence that the restraints employed may require further tuning to decrease the risk of overfitting. This consideration will be examined in future publications.

\subsection{Advantages of all-atom refinement with PrimeX}

All-atom refinement of moderate-resolution protein crystal structures with Prime $X$ resulted in a more than fourfold decrease in the number of clashes and a 17 -fold decrease in the number of severe clashes. This improvement in model quality was achieved without sacrificing the goodness of fit to the X-ray data as judged by the average $R_{\text {free }}$ values. Importantly, these models also display good summary statistics, so that the protein models comply with reasonable moleculargeometry expectations.

All-atom refinement with a force field allowed PrimeX refinement to fix errors that other refinement programs missed and provided a more accurate picture of critical protein features such as protein-ligand interactions, as illustrated in Figs. 1, 2 and 3. Resolution of clashes during refinement can help to 'push' the structure into the correct conformation, producing potentially remarkably large changes in conformation. They may also serve the role of preventing the structure from entering nonproductive conformations that are otherwise allowed in a less restrictive all-atom model.

These results also contain an indication of the limits of usefulness of the polish workflow. Fully $85 \%$ of the structures that entered the workflow with 50 or more total clashes (Table 3) resulted in an increase in $R_{\text {free }}$ (Tables 3 and 4). A large number of clashes is a warning sign that the structure may contain errors that could have negative consequences after the application of this refinement process.

\subsection{Reducing clashes in deposited X-ray crystal structure models}

The refinement programs REFMAC and phenix.refine both have the capability to use riding $\mathrm{H}$ atoms during refinement. One might reasonably expect that the use of this feature would have a positive impact on the issue of clashes in all-atom models. Unfortunately, the extent to which the riding $\mathrm{H}$ atom option is actually employed in refinement is impossible to determine in many cases, even after consulting both the primary literature references and the PDB entry. The lack of definitive information on this issue makes it nearly impossible to determine from these experiments whether these programs are capable of reducing clashes to the levels deduced to be reasonable goals from the ultrahigh-resolution structures or from the Prime $X$-refined structures. Comparing the frequency of clashes in Tables 3 and 4, one can only conclude that either (i) the riding $\mathrm{H}$ atom models and nonbonded contact restraints do not make as much difference as one might expect, (ii) the riding $\mathrm{H}$ atom option is very rarely used in these two programs or (iii) both are true. At the very least, one may safely conclude that some attribute of these programs or the way that they are being used must change before either of these programs can be considered to be part of the solution to this problem.

A role for $C N S$ in curbing clashes is also currently available. CNS can be employed with a more complex energy model than is routinely used by crystallographers. As well as deploying an Engh and Huber-based restraint system, $C N S$ is distributed with a force field that includes Lennard-Jones and electrostatic terms and that is regularly used for the determination of NMR structures (Linge et al., 2003). This force field has been employed to produce some very high quality NMR structures (see, for example, Nozinovic et al., 2010).

What else can be done to reduce the number of clashes in deposited structures? Perhaps the answer to this question resides in the standards for structure deposition in the PDB. A committee of the PDB is currently working on structurevalidation tools for use associated with the deposition of coordinates (Read et al., 2011). A reason for optimism is that the work of the Richardson group was included in the report of the committee. From the point of view of many users of protein structures, the deposition of all-atom models derived from protein crystal structures should be required. Clashes determined from an all-atom model should be, at the very least, measured and documented for all protein models that are deposited, just as other outliers to molecular-geometry standards are now listed in the entry header.

To achieve a higher standard for deposited protein structures, additional tools that are sensitive to close contacts could help. Prime $X$ can contribute to this goal, and the automated polish workflow presented here was designed to achieve this goal with the minimum of human intervention. However, the workflow was designed with the assumption that the crystal structure coordinates on which it would operate would be essentially free of errors in the main-chain tracing or sidechain rotamer selection. The prevalence of such errors in the data set examined here established the need for additional automated structure tools with the capability of making large changes in side-chain torsion angles or chain trace. Design of these workflows is in progress based on the tool set in the PrimeX refinement package (Bell et al., 2012). Although similar automated workflows exist for phenix.refine (Afonine et al., 2005) and indirectly for REFMAC (Murshudov et al., 2011) through the program SideAide in the PDB_REDO pipeline (Joosten et al., 2011), the frequency of clashes in structures refined by phenix.refine and REFMAC (Tables 3 and 5) raises the question whether these automated workflows can address the issue of all-atom clashes, no matter how capable and thorough these workflows are intended to be. While the program MolProbity (Davis et al., 2007; Chen, Arendall et al., 2010) is aimed at solving the right problem, these same results show that it is not being adequately employed to deal with the problem at hand.

The results presented here also highlighted a lack of attention to detail during structure determination in the ultrahigh-resolution protein data set. $\mathrm{H}$ atoms should not be placed in chemically impossible positions when, by all appearances, convincing electron density at those positions is 
lacking. In addition, clashes highlighted several clear errors in the coordinates of non-H atoms.

\section{Conclusion}

This study documents the existence of numerous unnecessary close contacts, including many severe ones, implicit in unitedatom models deposited in the PDB. Many of these close contacts can be readily removed, and doing so need not damage the agreement of the model with the observed X-ray diffraction data. Furthermore, attention to close contacts can bring to light errors in the placement of non-H atoms in protein crystal structure models. This latter point has also been made abundantly clear by over a decade of work by Jane Richardson, David Richardson and coworkers (Word et al., 1999, Davis et al., 2007; Chen, Arendall et al., 2010).

Clashes are detrimental to advances in the various branches of science that depend on protein crystal structure models, such as protein design and drug discovery. Normally, scientists working in these areas are not in a position to evaluate the reliability of each protein crystal structure, nor are they able to judge whether the effects of remediation of crystal structures might result in different sorts of errors. If crystallographers, who are of course in the best position to do so, do not address these issues, then eventually other scientists will. The result will be that protein crystallographers will have less control over the form in which their experimental results are archived and deployed. The advent of remediated database alternatives to the PDB (Joosten et al., 2009) is partially an outgrowth of this problem and an indication that this anticipated consequence is already becoming a reality.

Both the expected bond-length and bond-angle parameters of Engh \& Huber (1991) and the parameterization of van der Waals radii by Rowland \& Taylor (1996) are equally well grounded in high-resolution small-molecule crystallographic results. In protein crystallography the former geometric statistics are very strictly applied, while the latter receive much less attention. An understandable explanation for this contrast is the absence of $\mathrm{H}$-atom coordinates in classic protein crystal structure models. However, if the requirements for the highest quality protein models possible are to be met, the consideration of nonbonded contacts in all-atom models must become more prominent.

Expert assistance in workflow scripting by Shawn Watts and Dave Giesen, and helpful discussions with Tyler Day are gratefully acknowledged.

\section{References}

Abu Tarboush, N., Jensen, L. M., Feng, M., Tachikawa, H., Wilmot, C. M. \& Davidson, V. L. (2010). Biochemistry, 49, 9783-9791.

Adams, P. D., Pannu, N. S., Read, R. J. \& Brünger, A. T. (1997). Proc. Natl Acad. Sci. USA, 94, 5018-5023.

Adams, C. J., Pike, A. C., Maniam, S., Sharpe, T. D., Coutts, A. S., Knapp, S., La Thangue, N. B. \& Bullock, A. N. (2012). Proc. Natl. Acad. Sci. USA, 109, 3778-3783.
Afonine, P. V., Grosse-Kunstleve, R. W. \& Adams, P. D. (2005). CCP4 Newsl. 42, contribution 8 .

Afonine, P. V., Grosse-Kunstleve, R. W., Chen, V. B., Headd, J. J., Moriarty, N. W., Richardson, J. S., Richardson, D. C., Urzhumtsev, A., Zwart, P. H. \& Adams, P. D. (2010). J. Appl. Cryst. 43, 669-676.

Ali, A., Reddy, G. S., Nalam, M. N., Anjum, S. G., Cao, H., Schiffer, C. A. \& Rana, T. M. (2010). J. Med. Chem. 53, 7699-7708.

Allen, F. H. (2002). Acta Cryst. B58, 380-388.

Artz, J. D., Wernimont, A. K., Dunford, J. E., Schapira, M., Dong, A., Zhao, Y., Lew, J., Russell, R. G., Ebetino, F. H., Oppermann, U. \& Hui, R. (2011). J. Biol. Chem. 286, 3315-3322.

Attolino, E., Calderone, V., Dragoni, E., Fragai, M., Richichi, B., Luchinat, C. \& Nativi, C. (2010). Eur. J. Med. Chem. 45, 59195925.

Banks, J. L. et al. (2005). J. Comput. Chem. 26, 1752-1780.

Begley, D. W., Hartley, R. C., Davies, D. R., Edwards, T. E., Leonard, J. T., Abendroth, J., Burris, C. A., Bhandari, J., Myler, P. J., Staker, B. L. \& Stewart, L. J. (2011). J. Struct. Funct. Genomics, 12, 63-76.

Bell, J. A., Cao, Y., Gunn, J. R., Day, T., Gallicchio, E., Zhou, Z., Levy, R. \& Farid, R. (2012). International Tables for Crystallography, Vol. $F$, edited by E. Arnold, D. M. Himmel \& M. G. Rossmann, pp. 534-538. Chichester: John Wiley \& Sons.

Berman, H. M., Westbrook, J., Feng, Z., Gilliland, G., Bhat, T. N., Weissig, H., Shindyalov, I. N. \& Bourne, P. E. (2000). Nucleic Acids Res. 28, 235-242.

Biswas, T., Small, J., Vandal, O., Odaira, T., Deng, H., Ehrt, S. \& Tsodikov, O. V. (2010). Structure, 18, 1353-1363.

Blaszczyk, J., Li, Y., Shi, G., Yan, H. \& Ji, X. (2003). Biochemistry, 42, 1573-1580.

Bondi, A. (1964). J. Phys. Chem. 68, 441-451.

Bönisch, H., Schmidt, C. L., Bianco, P. \& Ladenstein, R. (2005). Acta Cryst. D61, 990-1004.

Borshchevskiy, V., Molseeva, E., Kuklin, A., Büldt, G., Hato, M. \& Gordeliy, V. (2010). J. Cryst. Growth, 312, 3326-3330.

Bosch, D. E., Kimple, A. J., Sammond, D. W., Muller, R. E., Miley, M. J., Machius, M., Kuhlman, B., Willard, F. S. \& Siderovski, D. P. (2011). J. Biol. Chem. 286, 3351-3358.

Bricogne, G., Blanc, E., Brandl, M., Flensburg, C., Keller, P., Paciorek, W., Roversi, P., Sharff, A., Smart, O. S., Vonrhein, C. \& Womack, T. O. (2011). BUSTER. Cambridge: Global Phasing Ltd.

Brünger, A. T. (1989). Acta Cryst. A45, 42-50.

Brünger, A. T. (1992). X-PLOR Version 3.1. A System for X-ray Crystallography and NMR. New Haven: Yale University Press.

Brünger, A. T., Adams, P. D., Clore, G. M., DeLano, W. L., Gros, P., Grosse-Kunstleve, R. W., Jiang, J.-S., Kuszewski, J., Nilges, M., Pannu, N. S., Read, R. J., Rice, L. M., Simonson, T. \& Warren, G. L. (1998). Acta Cryst. D54, 905-921.

Brünger, A. T., Clore, G. M., Gronenborn, A. M. \& Karplus, M. (1986). Proc. Natl Acad. Sci. USA, 83, 3801-3805.

Brünger, A. T. \& Karplus, M. (1988). Proteins, 4, 148-156.

Brünger, A. T., Karplus, M. \& Petsko, G. A. (1989). Acta Cryst. A45, 50-61.

Čapkauskaitè, E., Baranauskienè, L., Golovenko, D., Manakova, E., Gražulis, S., Tumkevičius, S. \& Matulis, D. (2010). Bioorg. Med. Chem. 18, 7357-7364.

Carrillo, D. R., Parthier, C., Jänckel, N., Grandke, J., Stelter, M., Schilling, S., Boehme, M., Neumann, P., Wolf, R., Demuth, H. U., Stubbs, M. T. \& Rahfeld, J. U. (2010). J. Biol. Chem. 391, 1419-1428.

Chatwell, L., Holla, A., Kaufer, B. B. \& Skerra, A. (2008). Mol. Immunol. 45, 1981-1994.

Chen, V. B., Arendall, W. B., Headd, J. J., Keedy, D. A., Immormino, R. M., Kapral, G. J., Murray, L. W., Richardson, J. S. \& Richardson, D. C. (2010). Acta Cryst. D66, 12-21.

Chen, Z., Pelc, L. A. \& De Cera, E. (2010). Proc. Natl Acad. Sci. USA, 107, 19278-19283.

Chen, B., Sysoeva, T. A., Chowdhury, S., Guo, L., De Carlo, S., Hanson, J. A., Yang, H. \& Nixon, B. T. (2010). Structure, 18, 14201430 . 
Chufán, E. E., Prigge, S. T., Siebert, X., Eipper, B. A., Mains, R. E. \& Amzel, L. M. (2010). J. Am. Chem. Soc. 132, 15565-15572.

Clasquin, M. F., Melamud, E., Singer, A., Gooding, J. R., Xu, X., Dong, A., Cui, H., Campagna, S. R., Savchenko, A., Yakunin, A. F., Rabinowitz, J. D. \& Caudy, A. A. (2011). Cell, 145, 969-980.

Compton, J. R., Legler, P. M., Clingan, B. V., Olson, M. A. \& Millard, C. B. (2011). Proteins, 79, 1048-1060.

Cook, W. J., Smith, C. D., Senkovich, O., Holder, A. A. \& Chattopadhyay, D. (2010). Acta Cryst. F66, 1426-1431.

Corminboeuf, O., Bezençon, O., Grisostomi, C., Remeň, L., RichardBildstein, S., Bur, D., Prade, L., Hess, P., Strickner, P., Fischli, W., Steiner, B. \& Treiber, A. (2010). Bioorg. Med. Chem. Lett. 20, 62866290.

Coulson, C. A. \& Thomas, M. W. (1971). Acta Cryst. B27, 1354-1359.

Crawley, S. W., Gharaei, M. S., Ye, Q., Yang, Y., Raveh, B., London, N., Schueler-Furman, O., Jia, Z. \& Côté, G. P. (2011). J. Biol. Chem. 286, 2607-2616.

Dasgupta, J., Blenkowska-Haba, M., Ortega, M. E., Patel, H. D., Bodevin, S., Spillmann, D., Bishop, B., Sapp, M. \& Chen, X. S. (2011). J. Biol. Chem. 286, 2617-2624.

Davis, I. W., Leaver-Fay, A., Chen, V. B., Block, J. N., Kapral, G. J., Wang, X., Murray, L. W., Arendall, W. B., Snoeyink, J., Richardson, J. S. \& Richardson, D. C. (2007). Nucleic Acid Res. 35, W375-W383.

Diebold, M. L., Koch, M., Loeliger, E., Cura, V., Winston, F., Cavarelli, J. \& Romier, C. (2010). EMBO J. 29, 3979-3991.

Eidam, O., Romagnoli, C., Caselli, E., Babaoglu, K., Pohlhaus, D. T., Karpiak, J., Bonnet, R., Shoichet, B. K. \& Prati, F. (2010). J. Med. Chem. 53, 7852-7863.

Empadinhas, N., Pereira, P. J., Albuquerque, L., Costa, J., Sá-Moura, B., Marques, A. T., Macedo-Ribeiro, S. \& da Costa, M. S. (2011). Mol. Microbiol. 79, 76-93.

Engh, R. A. \& Huber, R. (1991). Acta Cryst. A47, 392-400.

Esposito, L., Vitagliano, L., Sica, F., Sorrentino, G., Zagari, A. \& Mazzarella, L. (2000). J. Mol. Biol. 297, 713-732.

Feng, Z., Westbrook, J. \& Berman, H. M. (1998). NUCheck. Report NDB-407, Rutgers University, New Brunswick, New Jersey, USA.

Fenn, T. D., Ringe, D. \& Petsko, G. A. (2004). Biochemistry, 43, 64646474.

Fenn, T. D. \& Schnieders, M. J. (2011). Acta Cryst. D67, 957-965.

Fenn, T. D., Schnieders, M. J., Brunger, A. T. \& Pande, V. S. (2010). Biophys. J. 98, 2984-2992.

Fenn, T. D., Schnieders, M. J., Mustyakimov, M., Wu, C., Langan, P., Pande, V. S. \& Brunger, A. T. (2011). Structure, 19, 523-533.

Fokina, O., Chellamuthu, V.-R., Forchhammer, K. \& Zeth, K. (2010). Proc. Natl Acad. Sci. USA, 107, 19760-19765.

Fuhrmann, C. N., Daugherty, M. D. \& Agard, D. A. (2006). J. Am. Chem. Soc. 128, 9086-9102.

Gallicchio, E., Zhang, L. Y. \& Levy, R. M. (2002). J. Comput. Chem. 23, 517-529.

Ghosh, A., Rapp, C. S. \& Friesner, R. A. (1998). J. Phys. Chem. B, 102, 10983-10990.

Hakanpää, J., Linder, M., Popov, A., Schmidt, A. \& Rouvinen, J. (2006). Acta Cryst. D62, 356-367.

Hall, G., Bradshaw, T. D., Laughton, C. A., Stevens, M. F. \& Emsley, J. (2011). Protein Sci. 20, 210-215.

Han, L., Monné, M., Okumura, H., Schwend, T., Cherry, A. L., Flot, D., Matsuda, T. \& Jovine, L. (2010). Cell, 143, 404-415.

Hardegger, L. A., Kuhn, B., Spinnier, B., Anselm, L., Ecabert, R., Stihle, M., Gsell, B., Thoma, R., Diez, J., Benz, J., Plancher, J. M., Hartmann, G., Banner, D. W., Haap, W. \& Diederich, F. (2011). Agnew. Chem. Int. Ed. Engl. 50, 314-318.

Harmat, V., Domokos, K., Menyhárd, D. K., Palló, A., Szeltner, Z., Szamosi, I., Beke-Somfai, T., Náray-Szabó, G. \& Polgár, L. (2011). J. Biol. Chem. 286, 1987-1998.

Hee, C. S., Gao, S., Loll, B., Miller, M. M., Uchanska-Ziegler, B., Daumke, O. \& Ziegler, A. (2010). PLoS Biol. 8, e1000557.

Heldman, N., Vonshak, O., Sevier, C. S., Vitu, E., Mehlman, T. \& Fass, D. (2010). Protein Sci. 19, 1863-1876.
Hendrickson, W. A. (1985). Methods Enzymol. 115, 252-270.

Hooft, R. W. W., Sander, C. \& Vriend, G. (1996). Proteins, 26, 363-376.

Hooft, R. W. W., Vriend, G., Sander, C. \& Abola, E. E. (1996). Nature (London), 381, 272.

Husain, N., Obranic, S., Koscinski, L., Seetharaman, J., Babic, F., Bujnicki, J. M., Maravic Vlahovicek, G. \& Sivaraman, J. (2011). Nucleic Acids Res. 39, 1903-1918.

Jacques, D. A., Langley, D. B., Hynson, R. M., Whitten, A. E., Kwan, A., Guss, J. M. \& Trewhella, J. (2011). J. Mol. Biol. 405, 214-226.

Jiang, J.-S. \& Brünger, A. T. (1994). J. Mol. Biol. 243, 100-115.

Joosten, R. P. et al. (2009). J. Appl. Cryst. 42, 376-384.

Joosten, R. P., Joosten, K., Cohen, S. X., Vriend, G. \& Perrakis, A. (2011). Bioinformatics, 27, 3392-3398.

Jorgensen, W. L., Maxwell, D. S. \& Tirado-Rives, J. (1996). J. Am. Chem. Soc. 118, 11225-11236.

Kaminski, G., Friesner, R. A., Tirado-Rives, J. \& Jorgensen, W. L. (2001). J. Phys. Chem. B, 105, 6474-6487.

Ke, W., Sampson, J. M., Ori, C., Prati, F., Drawz, S. M., Bethel, C. R., Bonomo, R. A. \& van den Akker, F. (2011). Antimicrob. Agents Chemother. 55, 174-183.

Khan, H., Barna, T., Harris, R. J., Bruce, N. C., Barsukov, I., Munro, A. W., Moody, P. C. \& Scrutton, N. S. (2004). J. Biol. Chem. 279, 30563-30572.

Khan, M. Q., Sweeting, B., Mulligan, V. K., Arslan, P. E., Cashman, N. R., Pai, E. F. \& Chakrabartty, A. (2010). Proc. Natl Acad. Sci. USA, 107, 19808-19813.

Knight, J. L., Zhou, Z., Gallicchio, E., Himmel, D. M., Friesner, R. A., Arnold, E. \& Levy, R. M. (2008). Acta Cryst. D64, 383-396.

Ko, T.-P., Robinson, H., Gao, Y.-G., Cheng, C.-H., DeVries, A. L. \& Wang, A. H.-J. (2003). Biophys. J. 84, 1228-1237.

Konnert, J. H. (1976). Acta Cryst. A32, 614-617.

Konnert, J. H. \& Hendrickson, W. A. (1980). Acta Cryst. A36, 344-350.

Koparde, V. N., Scarsdale, J. N. \& Kellogg, G. E. (2011). PLoS One, 6, e15920.

Kumar, J. \& Mayer, M. L. (2010). J. Mol. Biol. 404, 680-696.

Kumar, D. V., Rai, R., Brameld, K. A., Somoza, J. R., Rajagopalan, R., Janc, J. W., Xia, Y. M., Ton, T. L., Shaghafi, M. B., Hu, H., Lehoux, I., To, N., Young, W. B. \& Green, M. J. (2011). Bioorg. Med. Chem. Lett. 21, 82-87.

Laskowski, R. A., MacArthur, M. W., Moss, D. S. \& Thornton, J. M. (1993). J. Appl. Cryst. 26, 283-291.

Lee, Y. T., Glazer, E. C., Wilson, R. F., Stout, C. D. \& Goodin, D. B. (2011). Biochemistry, 50, 693-703.

Lejon, S., Thong, S. Y., Murthy, A., AlQarni, S., Murzina, N. V., Blobel, G. A., Laue, E. D. \& Mackay, J. P. (2011). J. Biol. Chem. 286, 1196-1203.

Li, J., Abel, R., Zhu, K., Cao, Y., Zhao, S. \& Friesner, R. A. (2011). Proteins, 79, 2794-2812.

Li, H., Tong, S., Li, X., Shi, H., Ying, Z., Gao, Y., Ge, H., Niu, L. \& Teng, M. (2011). Cell Res. 21, 1039-1051.

Liebschner, D., Elias, M., Moniot, S., Fournier, B., Scott, K., Jelsch, C., Guillot, B., Lecomte, C. \& Chabrière, E. (2009). J. Am. Chem. Soc. 131, 7879-7886.

Lin, F.-Y., Liu, C.-I., Liu, Y.-L., Zhang, Y., Wang, K., Jeng, W. Y., Ko, T.-P., Cao, R., Wang, A. H.-J. \& Oldfield, E. (2010). Proc. Natl Acad. Sci. USA, 107, 21337-21342.

Linge, J. P., Williams, M. A., Spronk, C. A., Bonvin, A. M. \& Nilges, M. (2003). Proteins, 50, 496-506.

MacArthur, M. W. \& Thornton, J. M. (1996). J. Mol. Biol. 264, 11801195.

Matsumoto, K., Okamoto, K., Ashizawa, N. \& Nishino, T. (2010). J. Pharmacol. Exp. Ther. 336, 95-103.

Minasov, G., Wang, X. \& Shoichet, B. K. (2002). J. Am. Chem. Soc. 124, 5333-5340.

Morin, A., Kaufmann, K. W., Fortenberry, C., Harp, J. M., Mizoue, L. S. \& Meiler, J. (2011). Protein Eng. Des. Sel. 24, 503-516. 
Morita, H., Wanibuchi, K., Nii, H., Kato, R., Sugio, S. \& Abe, I. (2010). Proc. Natl Acad. Sci. USA, 107, 19778-19783.

Moulinier, L., Case, D. A. \& Simonson, T. (2003). Acta Cryst. D59, 2094-2103.

Murakawa, T., Machida, Y. \& Hayashi, H. (2011). J. Biol. Chem. 286, 2774-2784.

Murshudov, G. N., Skubák, P., Lebedev, A. A., Pannu, N. S., Steiner, R. A., Nicholls, R. A., Winn, M. D., Long, F. \& Vagin, A. A. (2011). Acta Cryst. D67, 355-367.

Murshudov, G. N., Vagin, A. A. \& Dodson, E. J. (1997). Acta Cryst. D53, 240-255.

Natesh, R., Manikandan, K., Bhanumoorthy, P., Viswamitra, M. A. \& Ramakumar, S. (2003). Acta Cryst. D59, 105-117.

Neu, U., Maginnis, M. S., Palma, A. S., Ströh, L. J., Nelson, C. D., Feizi, T., Atwood, W. J. \& Stehle, T. (2010). Cell Host Microbe, 8, 309-319.

Nicodeme, E. et al. (2010). Nature (London), 468, 1119-1123.

Nilges, M., Gronenborn, A. M., Brunger, A. T. \& Clore, G. M. (1988). Protein Eng. 2, 27-38.

Niu, W., Shu, Q., Chen, Z., Mathews, S., Di Cera, E. \& Frieden, C. (2010). J. Phys. Chem. B, 114, 16156-16165.

Nozinovic, S., Fürtig, B., Jonker, H. R., Richter, C. \& Schwalbe, H. (2010). Nucleic Acids Res. 38, 683-694.

Orita, I., Kita, A., Yurimoto, H., Kato, N., Sakai, Y. \& Miki, K. (2010). Proteins, 78, 3488-3492.

Ouellet, H., Kells, P. M., Ortiz de Montellano, P. R. \& Produst, L. M. (2011). Bioorg. Med. Chem. Lett. 21, 332-337.

Pannu, N. S. \& Read, R. J. (1996). Acta Cryst. A52, 659-668.

Patterson, A., Price, N. C. \& Nairn, J. (2010). Acta Cryst. F66, 14151420.

Paul, D., Chatterjee, A., Begley, T. P. \& Ealick, S. E. (2010). Biochemistry, 49, 9922-9934.

Paz, S., Tizón, L., Otero, J. M., Llamas-Saiz, A. L., Fox, G. C., van Raaij, M. J., Lamb, H., Hawkins, A. R., Lapthorn, A. J., Castedo, L. \& González-Bello, C. (2011). ChemMedChem, 6, 266-272.

Peters, C., Brejc, K., Belmont, L., Bodey, A. J., Lee, Y., Yu, M., Guo, J., Sakowicz, R., Hartman, J. \& Moores, C. A. (2010). EMBO J. 29, 3437-3447.

Pizzo, E., Merlino, A., Turano, M., Russo Krauss, I., Coscia, F., Zanfardino, A., Varcamonti, M., Furia, A., Giancola, C., Mazzarella, L., Sica, F. \& D'Alessio, G. (2010). Biochem. J. 433, 345-355.

Priestle, J. P. (2003). J. Appl. Cryst. 36, 34-42.

Privé, G. G., Anderson, D. H., Wesson, L., Cascio, D. \& Eisenberg, D. (1999). Protein Sci. 8, 1400-1409.

Radford, R. J., Lawrenz, M., Nguyen, P. C., McCammon, J. A. \& Akif Tezcan, F. (2011). Chem. Commun. 47, 313-315.

Read, R. J. (1986). Acta Cryst. A42, 140-149.

Read, R. J. et al. (2011). Structure, 19, 1395-1412.

Romano, K. P., Ali, A., Royer, W. E. \& Schiffer, C. A. (2010). Proc. Natl Acad. Sci. USA, 107, 20986-20991.

Roosild, T. P., Castronovo, S., Healy, J., Miller, S., Pliotas, C., Rasmussen, T., Bartlett, W., Conway, S. J. \& Booth, I. R. (2010). Proc. Natl Acad. Sci. USA, 107, 19784-19789.

Rowland, R. S. \& Taylor, R. (1996). J. Phys. Chem. 100, 7384-7391.

Ryan, A. J., Ghuman, J., Zunszain, P. A., Chung, C. W. \& Curry, S. (2011). J. Struct. Biol. 174, 84-91.

Sainsbury, L., Bird, L., Rao, V., Shepherd, S. M., Stuart, D. I., Hunter, W. N., Owens, R. J. \& Ren, J. (2010). J. Mol. Biol. 405, 173-184.
Schmelz, S. (2010). PhD Thesis. University of St Andrews, Fife, Scotland.

Schnieders, M. J., Fenn, T. D. \& Pande, V. S. (2011). J. Chem. Theory Comput. 7, 1141-1156.

Schröder, G. F., Levitt, M. \& Brunger, A. T. (2010). Nature (London), 464, 1218-1222.

Sendovski, M., Kanteev, M., Shuster Ben-Yosef, V., Adir, N. \& Fishman, A. (2010). Acta Cryst. F66, 1101-1103.

Sheldrick, G. M. \& Schneider, T. R. (1997). Methods Enzymol. 277, 319-343.

Shinobu, A., Palm, G. J., Schierbeek, A. J. \& Agmon, N. (2010). J. Am. Chem. Soc. 132, 11093-11102.

Spronk, C. A. E. M., Nabuurs, S. B., Krieger, E., Vriend, G. \& Vuister, G. W. (2004). Prog. Nucl. Magn. Reson. Spectrosc. 45, 315-337.

Sun, M., Larivière, L., Dengl, S., Mayer, A. \& Cramer, P. (2010). J. Biol. Chem. 285, 41597-41603.

Sun, J. \& Weis, W. I. (2011). J. Mol. Biol. 405, 519-530.

Swiecki, M., Scheaffer, S. M., Allaire, M., Fremont, D. H., Colonna, M. \& Brett, T. J. (2011). J. Biol. Chem. 286, 2987-2997.

Takeda, K., Kusumoto, K., Hirano, Y. \& Miki, K. (2010). J. Struct. Biol. 169, 135-144.

Thompson, M. K., Davis, M. F., de Serrano, V., Nicoletti, F. P., Howes, B. D., Smulevich, G. \& Franzen, S. (2010). Biophys. J. 99, 15861595.

Tong, Y., Tempel, W., Wang, H., Yamada, K., Shen, L., Senisterra, G. A., MacKenzie, F., Chishti, A. H. \& Park, H. W. (2010). Proc. Natl Acad. Sci. USA, 107, 20346-20351.

Touw, W. G. \& Vriend, G. (2010). Acta Cryst. D66, 1341-1350.

Tronrud, D. E., Berkholz, D. S. \& Karplus, P. A. (2010). Acta Cryst. D66, 834-842.

Vaguine, A. A., Richelle, J. \& Wodak, S. J. (1999). Acta Cryst. D55, 191-205.

Wallace, B. D., Wang, H., Lane, K. T., Scott, J. E., Orans, J., Koo, J. S., Venkatesh, M., Jobin, C., Yeh, L.-A., Mani, S. \& Redinbo, M. R. (2010). Science, 330, 831-835.

Wang, J., Dauter, M., Alkire, R., Joachimiak, A. \& Dauter, Z. (2007). Acta Cryst. D63, 1254-1268.

Wang, Y. \& Guo, H.-C. (2010). J. Mol. Biol. 403, 120-130.

Watenpaugh, K. D., Sieker, L. C., Herriott, J. R. \& Jensen, L. H. (1973). Acta Cryst. B29, 943-956.

Weis, W. I., Brünger, A. T., Skehel, J. J. \& Wiley, D. C. (1990). J. Mol. Biol. 212, 737-761.

Word, J. M., Lovell, S. C., LaBean, T. H., Taylor, H. C., Zalis, M. E., Presley, B. K., Richardson, J. S. \& Richardson, D. C. (1999). J. Mol. Biol. 285, 1711-1733.

Xiang, Y., Huang, R.-H., Liu, X. Z., Zhang, Y. \& Wang, D.-C. (2004). J. Struct. Biol. 148, 86-97.

Yang, W., Bell, S. G., Wang, H., Zhou, W., Bartlam, M., Wong, L.-L. \& Rao, Z. (2010). Biochem. J. 433, 85-93.

Yang, F., West, A. P. Jr \& Bjorkman, P. J. (2011). J. Struct. Biol. 174, 239-244.

Yoshida, H., Takeda, K., Izumori, K. \& Kamitori, S. (2010). Protein Eng. Des. Sel. 23, 919-927.

Zhou, H., Brock, J., Casarotto, M. G., Oakley, A. J. \& Board, P. G. (2011). J. Biol. Chem. 286, 4271-4279.

Zhu, K., Shirts, M. R. \& Friesner, R. A. (2007). J. Chem. Theory Comput. 3, 2108-2119. 